\title{
Measurement ANd ANAlysis Of The Surface ENERgy Budget FOR ARM FIELD EXPERIMENTS
}

\author{
Kenneth E. Kunkel \\ Illinois State Water Survey \\ University of Illinois \\ Champaign, Illinois
}

Final Report to

Los Alamos National Laboratory

Contract 9-XG2-X3799-1

$\div$

\section{DISCLAIMER}

This report was prepared as an account of work sponsored by an agency of the United States Government. Neither the United States Government nor any agency thereof, nor any of their employees, makes any warranty, express or implied, or assumes any legal liability or responsibility for the accuracy, completeness, or usefulness of any information, apparatus, product, or process disclosed, or represents that its use would not infringe privately owned rights. Reference herein to any specific commercial product, process, or service by trade name, trademark, manufacturer, or otherwise does not necessarily constitute or imply its endorsement, recommendation, or favoring by the United States Government or any agency thereof. The views and opinions of authors expressed herein do not necessarily state or reflect those of the United States Government or any agency thereof. 


\section{DISCLAIMER}

Portions of this document may be illegible in electronic image products. Images are produced from the best available original document. 


\begin{abstract}
The objective of this study is to conduct experiments to investigate the scaling properties of surface-atmosphere interactions and feedbacks as they relate to regional fluxes of heat and water vapor. This is part of the U.S. Department of Energy's Atmospheric Radiation Measurement program. To achieve this objective, two field campaigns were conducted in northeastern Oregon during June 1991 and June 1992. Analysis of the data collected during these campaigns revealed the following:

- Fluxes over a dry, semi-arid grass/brush area show only small spatial heterogeneity - Fluxes over an irrigated farm were dependent on crop type and stage of development. In particular, fluxes over row crops such as potatoes and corn were very similar to each other, but somewhat different than fluxes over wheat and alfalfa. In general, higher latent and lower sensible heat fluxes were experienced over wheat and alfalfa compared to corn and potatoes.

- Meteorological factors had a major influence on fluxes. In particular, significantly higher latent heat fluxes were experienced on days with moderate winds compared to days with light winds over the irrigated farm. This was presumably due to the advection of sensible heat from the surrounding dry rangeland.
\end{abstract}




\section{Introduction}

The accurate parameterization of the land surface energy budget within general and regional scale atmospheric circulation models is complicated by the presence of significant sub-grid scale heterogeneity in land surface characteristics. Current generation models make no attempt to parameterize this sub-grid scale heterogeneity. Approaches to addressing this problem include statistical methods (e.g. Avissar, 1993) and mosaic methods (e.g. Claussen, 1991). An overall objective of this study is to test proposed approaches and/or develop new approaches to address this problem through the analysis of an experimental data set collected at a site in northeast Oregon with substantial spatial heterogeneity. This experiment was conducted as part of the U.S. Department of Energy's (DOE) Atmospheric Radiation Measurements (ARM) program.

This report gives a brief summary of progress. It also describes the observed heterogeneity in the surface energy budget and relates the spatial differences to vegetation properties and synoptic scale meteorological conditions for measurements obtained during June 1992.

\section{Tasks and Progress}

- Task 1.0 - Attend planning meetings.

Planning meetings were attended in Denver, CO (October 1991), Boardman, OR (June 1992), and Norman, OK (March 1992).

- Task 2.0 - Participate in annual field campaign.

I participated in the June 1992 field campaign near Boardman, OR. I set up and operated a network of 12 flux stations for this 3-week campaign. No field campaign was undertaken in 1993.

- Task 2.1 - Assist with supervision of LANL meteorological measurement systems.

For the June 1992 campaign, I brought four of my own flux stations for involvement in the field measurements. Eight flux stations were brought by LANL. I assumed responsibility for their set-up and operation. All 12 stations were operated successfully, with little missing or erroneous data.

- Task 2.2 - Assist in setting quality control guidelines for the field campaign and with identifying quality data for analysis.

The reduction of the 1991 and 1992 field campaign data was performed by a research assistant under my supervision. I personally reviewed all data and made judgements about the quality of those data.

- Task 3.0 - Participate in planning and executing analysis methodology in order to facilitate program goals. 
The analysis of the flux data collected during the 1991 and 1992 field campaigns was completed in cooperation with Fairley Barnes and William Dugas. Principal findings are as follows:

- Fluxes over a dry, semi-arid grass/brush area show only small spatial heterogeneity.

- $\quad$ Fluxes over an irrigated farm were dependent on crop type and stage of development. In particular, fluxes over row crops such as potatoes and corn were very similar to each other, but somewhat different than fluxes over wheat and alfalfa. In general, higher latent and lower sensible heat fluxes were experienced over wheat and alfalfa compared to corn and potatoes.

- Meteorological factors had a major influence on fluxes. In particular, significantly higher latent heat fluxes were experienced on days with moderate winds compared to days with light winds over the irrigated farm. This was presumably due to the advection of sensible heat from the surrounding dry rangeland.

- Task 4.0 - Participate in writing scientific papers.

A list of publications prepared under this project is given below.

\section{Publications}

Barnes, F.J., K.E. Kunkel, D. Cooper, L. Hipps, E. Swiatek, and W. Porch, 1992: Variability of surface fluxes over a heterogeneous desert grassland. Third Symposium on Global Change Studies, January 5-10, Atlanta, GA.

Barnes, F.J., W. Porch, S. Tarbox, K.E. Kunkel, R.W. Scott, W.A. Dugas, R. Hicks, P. Larson, and C. Riemann, 1993: Energy balance components of irrigated crops in north-central Oregon. Preprints, Fourth Symposium on Global Change Studies, January 17-22, Anaheim, CA.

Doran, J.C., F.J. Barnes, R.L. Coulter, T.L. Crawford, D.D. Baldocchi, L. Balick, D.R. Cook, D. Cooper, R.J. Dobosy, W.A. Dugas, L. Fritschen, R.L. Hart, L. Hipps, J.M. Hubbe, W. Gao, R. Hicks, R.R. Kirkham, K.E. Kunkel, M.J. Martin, T.P. Meyers, W. Porch, J.D. Shannon, W.J. Shaw, E. Swiatek, and C.D. Whiteman, 1992: The Boardman Regional Flux Experiment. Bull. Amer. Meteor. Soc., 73, 1785-1795.

Kunkel, K.E., 1992: Measurements and Analysis of the Surface Energy Budget for ARM Field Experiment. Annual Report under Los Alamos National Laboratory subcontract 9-XG2-X3799-1, $72 \mathrm{pp}$. [Available from Illinois State Water Survey.] 
Porch, W., F. Barnes, M. Buchwald, J. Stephens, J. Archuleta, and K. Kunkel, 1993: Application of spatially averaging optical techniques to the study of short-term flux changes associated with Clouds. Fourth Symposium on Global Climate Studies, 73rd Annual Meeting, American Meteorological Society, Anaheim, CA, 6 pp.

Porch, W., D. Cooper, M. Buchwald, W. Clements, F. Barnes, C. Doran, W. Shaw, J. Hubbe, R. Coulter, T. Martin, and K. Kunkel, 1992: Spatially averaged heat flux convergence measurements at the ARM regional flux experiment. Third Symposium on Global Change Studies, January 5-10, Atlanta, GA.

\section{Analysis of 1992 Field Campaign Data}

The results of the analysis of the 1992 field campaign data have not appeared yet in published form. The remaining part of this report describes these results. A paper including these results will be submitted soon to a journal.

\section{Experiment Description}

A. Site

This site has been described in Doran et al. (1992). Briefly, it is located in northeastern Oregon near Boardman. A large irrigated farm ( $6000 \mathrm{ha})$ is bordered on the west, south and east by a sagebrush steppe area. The terrain is generally flat to gently rolling with a slight upslope of $0.75 \%$ to the south. The farm consists of center pivot irrigated fields approximately 50 ha each in size.

Soils are generally sandy and well-drained. The summer climate can be characterized as very warm and dry. Annual precipitation is $230 \mathrm{~mm}$ with November and March being the wettest months. Prevailing winds during June are west to southwest.

The circular fields were continuously irrigated by a center pivot irrigation system. The irrigation boom traveled at the rate of 1 revolution $/ 31 \mathrm{hr}$. Each boom passage resulted in a water application of approximately $15 \mathrm{~mm}$.

\section{Methods}

Sensible and latent heat fluxes were measured using the Eddy Correlation (EC) technique and the Bowen-Ratio Energy Balance (BREB) technique. These are described below. 


\section{A. Eddy Correlation Measurements}

Each EC system was mounted 3.2 meters above the soil surface and consisted of a Krypton hygrometer, a one-dimensional sonic anemometer, and a $12.5 \mu \mathrm{m}$ fine-wire thermocouple (manufactured by Campbell Scientific Inc.) The measurements of the covariance of the vertical wind velocity and water vapor concentration fluctuations, $w^{\prime} \rho^{\prime}{ }_{w}$, and the vertical wind velocity and temperature fluctuations, w'T,' were made at $10 \mathrm{~Hz}$ and averaged over 15 -minute intervals. Sensible $(\mathrm{H})$ and latent (LE) heat fluxes were calculated from the covariances as

$$
\begin{aligned}
& H=p c_{p} \overline{w^{\prime} T^{\prime}} \\
& L E=L \overline{w^{\prime} p^{\prime}}
\end{aligned}
$$

where $\rho=$ air density, $c_{p}=$ specific heat of air, $L=$ latent heat of vaporization and the overbar represents a time average. The latent heat flux was corrected for the effects of oxygen absorption at the wavelength of the Krypton hygrometer emission lines.

Table 1 gives a list of other measurements made at two of the EC sites (potato field 12 and wheat field 26).

\begin{tabular}{|c|c|c|}
\hline Variable & Sensor Type & Manufacturer \\
\hline Temperature & Thermistor & Campbell Scientific \\
\hline Relative Humidity & Thin Film & Campbell Scientific \\
\hline Wind Speed & Cup Anemometer & Climatronics \\
\hline Wind Direction & Vane & Climatronics \\
\hline Solar Radiation & $\begin{array}{c}\text { Photo-sensitive silicon } \\
\text { detector }\end{array}$ & $L i-C o r$ \\
\hline Net Radiation & $\begin{array}{c}\text { Thermopile with } \\
\text { hemispherical shielding }\end{array}$ & $\begin{array}{l}\text { REBS } \\
R E B S\end{array}$ \\
\hline Soil Heat Flux & Heat flux plates & Campbell Scientific \\
\hline Soil Temperature & Thermocouple & Campbell Scientific \\
\hline
\end{tabular}

Table 1. Meteorological measurements at potato field 12 and wheat field 26. 


\section{B. Bowen Ratio Measurements}

$$
R_{n}=L E+H+G
$$

The energy balance of a two-dimensional surface can be described as follows where $R_{n}$ is net radiation and $G$ is soil heat flux density. $R_{n}$ toward the surface and $E, H$, and $G$ away from the surface were considered positive.

If potential temperature $(T)$ and specific humidity $(q)$ measurements are made at two heights above the surface near the ground with the same height interval between sensors, the Bowen ratio $(\beta)$ can be calculated as:

$$
\beta=\frac{c_{p} K_{h} \Delta T}{L K_{w} \Delta q}
$$

where $\mathrm{K}_{\mathrm{h}}$ and $\mathrm{K}_{\mathrm{w}}$ are eddy diffusivities for heat and water vapor, respectively, and $\Delta \mathrm{T}$ and $\Delta \mathrm{q}$ are finite differences. If it is assumed that $\mathrm{K}_{\mathrm{h}}=\mathrm{K}_{\mathrm{w}}$ and the vertical profile shapes of $\mathrm{T}$ and $\mathrm{q}$ are similar, Eqs. (3) and (4) can be combined into the following:

$$
L E=\frac{R_{n}-G}{1+\beta}
$$

$\mathrm{H}$ can then be calculated using Eq. (3).

The four BREB systems used in this study were similar to those used by Tanner et al. (1987), Dugas et al. (1991), and Dugas (1992). The $\Delta \mathrm{T}$ [eq. (4)] was measured using differentially-wired, unaspirated, unshielded fine-wire (diameter $=25.4 \mu \mathrm{m}$ ) chromel/constantan thermocouple. One thermocouple was on one of two measurement arms. Except for one system, three pairs of thermocouple were used and the average $\Delta \mathrm{T}$ was used. One system had only one pair of thermocouple.

Dewpoint temperature for each arm was measured using one cooled-mirror hygrometer (Model DEW 10, General Eastern, Watertown, MA) that sequentially sampled air from the height of each measurement arm for $1 \mathrm{~min}$. Dewpoint temperature and $\Delta T$ were measured for the last 30 $\mathrm{s}$ of each minute. The mean $\mathrm{q}$ was calculated from dewpoint temperatures. The $\Delta \mathrm{q}$ [eq. (4)] for each 15-min. period was calculated from the difference in the mean $\mathrm{q}$ for each height.

Measurements of $R_{n}$ were made on each BREB system using a Model $Q^{*} 6$ net radiometer (REBS, Seattle, WA). Sensor sensitivity was determined by intercomparison.

The $\mathrm{G}$ was calculated from the mean soil heat flux at 0.05 or $0.1 \mathrm{~m}$ measured using two Model HFT-1 soil heat flux plates (REBS) buried near each BREB system and from the energy 
storage from the surface to the plate depth. Factory plate sensitivities were used and corrections were made for plate shape and for differences in plate and soil thermal conductivity (Philip 1961). Storage was calculated from soil temperature and soil heat capacity $\left(1.5 \mathrm{MJ} \mathrm{m}^{-3} \mathrm{~K}^{-1}\right)$. Soil heat capacity was assumed to be constant across time and fields and calculated from gravimetric soil water content and bulk density measurements in an alfalfa field on 1 June 1991 (Unpublished data, David Whiteman, PNL).

All measurements were averaged for 15 -min. periods. The was evaluated for rejection due to $\beta=1.0$ using criteria described by Ohmura (1982). The LE was calculated for all 15 -minute periods where the $\beta$ was not rejected. For periods when the $\beta$ was rejected (typically a couple of hours in the early morning and late-afternoon when LE was low), LE was calculated by linear interpolation from the LE immediate before and after the rejection period. Daily LE totals were calculated from 15-minute LE's. Periods for totalizing were defined by periods with data common to all stations.

\section{Instrument Comparison}

Three of the four BREB stations and all EC stations were set up in a vigorously growing alfalfa field. The stations were located approximately $60 \mathrm{~m}$ into the field from the east field edge. A common data period, when all stations were operational, was used for the subsequent analysis. This period was 1945 LDT, Day 153 to 1515 LDT, Day 154. Fluxes were averaged over 15-minute intervals.

An analysis of the EC data alone was performed first. For each 15-minute period, an overall average flux was calculated as an average of all stations. For each station, a scatter plot of the station data vs. the overall average was examined. In addition, a linear regression analysis was performed. The comparison of sensible heat flux revealed insignificant differences among the stations. However, there were significant differences for latent heat flux and it was necessary to derive adjustment coefficients. Two separate comparisons were performed to derive these coefficients: one for the LE data and the other for the standard deviations of $q\left(\sigma_{q}\right)$ and $w\left(\sigma_{w}\right)$. Separate adjustment factors were derived for the two comparisons.

The resulting adjustment coefficients for LE should be similar to the adjustment coefficients for the product of $\sigma_{\mathrm{q}} \sigma_{\mathrm{w}}$. In general, $\sigma_{\mathrm{q}} \sigma_{\mathrm{w}}$ adjustment factors may be more accurate because of smaller statistical uncertainty (Wyngaard, 1973).

Figure 1 compares the adjustment coefficients for the LE comparison with the coefficients for the $\sigma_{q} \sigma_{w}$ comparison. Coefficients for eight of the ten stations are similar in magnitude (within 3 percent). Two stations ( 6 and 11) exhibit larger differences. A closer examination of station 11 data indicates that $\sigma_{\mathrm{q}}$ data during the nighttime hours are anomalously high. This results in a larger value of the coefficient for $\sigma_{\mathrm{q}} \sigma_{\mathrm{w}}$. A separate comparison was done for this station using only daytime hours (higher LE values). The revised comparison (data point '11D' in Fig. 1) is much closer for 
station 11. The cause of the higher nighttime $\sigma_{\mathrm{q}}$ values is unknown. However, it does not appear to have an effect on daytime LE values. Therefore, use of correction factors based on the daytime analysis would appear justified. This leaves station 6 as the only remaining outlier. A close inspection of the data does not suggest any possible cause for the large differences between the two methods. For that station, the data for the subsequent field experiment must be viewed with caution. However, the favorable comparison for the remaining stations lends confidence in applying the coefficients to the subsequent field experiment data. In most cases, the standard errors of the slopes are smaller for $\sigma_{q} \sigma_{w}$ than for LE; thus, use of factors from the $\sigma_{q} \sigma_{w}$ comparison is preferred.

A separate comparison of flux values from the BREB stations indicated insignificant differences among these stations. The final step of the analysis was a comparison EC and BREB data. This comparison indicated that the EC LE data are low by an average of $21 \%$.

The EC fluxes in the subsequent experiment were adjusted based on the $\sigma_{q} \sigma_{w}$-derived factors. Because of uncertainty in the adjustment factor, data from station 6 (wheat field 34) should be viewed with caution. The EC LE fluxes were low compared to the BREB LE values. We assumed that the BREB data are more accurate. Thus, further adjustment by a factor of $1.26(1 / 0.79)$ was applied to subsequent EC field data.

\section{Flux Variability at EC Station Sites}

An analysis of the variability in sensible and latent heat fluxes was performed. In this section, the variability among the sites with EC stations is covered. Scatter plots of 15 min sensible and latent heat fluxes for each field-to-field pair were examined for differences. A summary of differences is given below.

\section{Same Crop}

Very small differences in sensible heat flux were observed between fields with the same crop. Figures 2-5 show examples for wheat fields 26 and 19, wheat fields 26 and 34, potato fields 12 and 47, and alfalfa fields 43 and 44, respectively. Wheat fields 19, 26, and 34 exhibit negligible differences in sensible heat flux. The same conclusion is true for the two potato fields and alfalfa fields. There is considerably more scatter in the plots of latent heat flux. However, differences between fields with the same crop are very small. Negligible differences are observed between potato fields 12 and 47 and alfalfa fields 43 and 44 . There are minor differences among the wheat fields with

slightly higher fluxes observed in field 34 and somewhat lower fluxes in wheat field 19. 


\section{Corn vs, Potatoes}

Only minor differences between sensible and latent heat fluxes over corn and potatoes are observed. Figure 6 shows the comparison between corn field 47 and potato field 12 . Sensible heat flux is slightly more negative at night over potatoes compared to corn, particularly with moderate winds. Similarly, latent heat flux is somewhat higher during the day over potatoes, particularly with moderate winds.

\section{Wheat vs. Potatoes}

Larger differences are observed between wheat and potatoes. Figure 7 shows the comparison between wheat field 26 and potato field 12 . For sensible heat flux, the most significant differences are observed at night. Sensible heat flux over wheat is considerably more negative (approximately double the magnitude) compared to potatoes. Corresponding to this difference, latent heat flux at night is considerably larger over wheat. In addition, latent heat flux tends to be somewhat higher throughout the day over wheat compared to potatoes.

\section{Alfalfa vs. Potatoes}

This comparison is similar to the wheat vs. potatoes comparison, although the differences are not quite as large. Figure 8 shows the comparison between alfalfa field 43 and potato field 47 . As with wheat, sensible heat flux at night is slightly larger in magnitude (i.e. more negative) over alfalfa compared to potatoes. Also, latent heat flux tends to be somewhat higher throughout the day, particularly with moderate winds, over alfalfa.

\section{Corn vs. Wheat}

This comparison is similar to that of wheat vs. potatoes. Figure 9 shows the comparison between corn field 48 and wheat field 26 For sensible heat flux, values are larger in magnitude at night over wheat compared to corn. There are also larger positive values of latent heat flux at night over wheat. In addition, latent heat flux values are higher overall over wheat compared to corm.

\section{Alfalfa vs. Corn}

This comparison is similar to that of wheat vs. corn. Figure 10 shows the comparison between alfalfa field 43 and corn field 48. At night, sensible heat flux is more negative over alfalfa compared to corn, particularly with moderate winds.. Coincident with this, slightly higher latent heat flux is observed at night over alfalfa. In addition, latent heat flux is generally somewhat higher over alfalfa during the day, particularly with moderate winds. 


\section{Wheat vs. Alfalfa}

Fluxes over these crops are quite similar. Figure 11 shows the comparison between wheat field 26 and alfalfa field 43. Somewhat more negative sensible heat flux values are observed at night over wheat compared to alfalfa. Coincident with this, latent heat flux at night is slightly higher over wheat, particularly with moderate winds. Latent heat flux during the day is very similar between two crops.

\section{Summary of EC Site-to-Site Comparison}

Most of the observed differences can be explained by crop coverage and/or geometry. The two row crops, corn and potatoes, were in an intermediate stage of development and complete canopy coverage had not been yet been achieved. In general, slightly lower latent heat flux is observed over these two crops compared to wheat and alfalfa. We hypothesize that maximum transpiration rates are similar among the four crops. The observed differences during the day are assumed to be primarily due to lower evaporation rates from the bare ground over the two row crops compared to the complete canopy of wheat and alfalfa. Lower daytime net radiation is measured over potatoes compared to wheat (Figure 12). This is caused by higher surface temperatures (as indicated by infrared temperature measurements) over potatoes compared to wheat, presumably due to higher temperatures in the furrows between the rows. We hypothesize that the higher average surface temperature is due to reduced ventilation, caused by shielding by the crop that reduces the rate of energy transfer into the free atmosphere above the canopy and to reduced moisture availability caused by top soil drying between irrigation. The lower latent heat flux results from less available energy and higher sensible heat flux for the bare portion of the surface.

Differences at night are more intriguing. Over both wheat and potatoes, net radiation values are quite small and similar in magnitude (Figure 11). However, evaporation rates are rather high, particularly with moderate winds. The energy for evaporation is being supplied primarily by downward transfer of sensible heat. Latent heat flux is much higher at night over wheat than over corn and potatoes. Values for alfalfa are between wheat and the two row crops. We hypothesize that at night the stomatal resistance is large due to the lack of solar radiation to stimulate the stomates in the leaves to open. Thus, we might expect that evaporation from the soil would be relatively more important at night than during the day. We might also hypothesize that ventilation of the soil over wheat and alfalfa will be much more restricted than over the partially vegetated corn and potatoes. However we observe that evaporation rates remain higher over wheat and alfalfa than over corn and potatoes. Thus it would appear that even at night, transpiration makes the most important contribution to evapotranspiration and that the stomatal resistance remains low enough to allow substantial transpiration. 


\section{Flux Variability at BREB Sites Compared to EC Sites}

This discussion will focus on the mid-day hours, because BREB flux values are often unavailable at night. Figure 13 shows mid-day sensible and latent heat flux averaged over the time period 1100-1500 LDT for three of the BREB stations: corn fields 35 and 49, and alfalfa field 36. Also shown are similar values for the following EC sites: corn field 48 , wheat field 26 , potato field 12 , and alfalfa field 44.

The flux values at the two BREB corn sites are very similar. Latent heat flux over field 35 is slightly higher than over field 49 . However, the differences are not great, and the day-to-day variation is similar. When compared with the EC corn site (field 48), similar magnitudes are observed. However, there are some subtle differences. Sensible heat flux is consistently lower at field 48 than at the BREB fields. Although the absolute differences are relatively small (averaging 40 to $50 \mathrm{~W} / \mathrm{m}^{2}$ ), the percentage differences are rather large, with sensible heat flux at the BREB sites approximately 2 to 3 times greater than at the EC site. There are subtle differences in the day-to-day behavior, with the largest differences observed on days 159-161. Latent heat flux is slightly lower on days $157,158,162$, and 163 , but somewhat higher on days 159-161 at the EC site. The differences in day-to-day behavior may be caused by differences in wind speed. Mid-day wind speeds on days 159-161 were in the moderate range of 4 to $8 \mathrm{~m} / \mathrm{s}$. On the other four days, mid-day wind speeds were generally less than $4 \mathrm{~m} / \mathrm{s}$. Table 2 lists the mid-day averages of wind speed and other meteorological variables.

Although the magnitude of the differences is not large, they are intriguing and were investigated further. One possible explanation is that there is a wind-dependent calibration error in the EC systems. The Appendix discusses one problem that was discovered resulting from a computational approximation that is suggested by the EC system manufacturer. This approximation apparently can result in a significant underestimation of latent heat flux, which appears to be greatest under light wind conditions. The analysis in the appendix found errors as large as $14 \%$ under light winds, although the average error under light winds was approximately $8 \%$. Under moderate winds the errors were less than $3 \%$ and considered insignificant. Since the intercomparison test (described in Section 4) was conducted under light winds, the resulting adjustment coefficients could result in an overcompensation in more moderate wind situations. This is consistent with the observed differences between the EC corn site and the BREB sites, with higher LE values over the EC site under moderate winds. Further evidence for a possible calibration problem is shown in Table 3 . This gives values of the energy imbalance $\left(R_{n}-L E-H-G\right)$ at two EC sites: potato field 12 and wheat field 26 , for mid-day. There is a clear dependence on wind speed, with positive values of the energy imbalance observed on light wind days $(157,158,162,163)$ and negative values on moderate wind days $(159,160,161)$. This behavior is consistent with a wind-dependent calibration error.

Although this computational approximation may be partially responsible for the differences, it does not fully explain them. This potential computational problem would not affect sensible heat flux. There are no known instrumental problems with the EC sensible heat flux instrumentation that could result in the observed differences. Of course, EC instrumental problems cannot be discounted 
with certainty. Another possible explanation is that the assumptions used in the BREB calculations may not be very accurate under the highly advective conditions observed with moderate winds. The two relevant assumptions are that the exchange coefficients for heat and water vapor are equal and the vertical profiles of temperature and water vapor are similar in shape. Other investigators have found that these assumptions may not be valid under advective conditions (Rosenberg et al., 1978), but we cannot resolve this issue with the available data set. Thus, these differences remain unresolvable.

The observed differences between the EC and BREB corn sites are rather small. However, the observed dependence of fluxes on wind speed is considerably larger over the other three crops, and thus the resolution of these differences becomes more important when discussing the behavior in potatoes, wheat, and alfalfa. For these three crops, latent heat flux is much higher on days 159-161 than on the other four days. Corresponding to this, sensible heat flux tends to be lowest on these three days. The BREB alfalfa site (field 35) provides some support for this behavior. Although the alfalfa field 35 crop canopy was increasing significantly during this period, the changes in latent heat flux during days 160-163 are similar over this field compared to the potato, wheat, and alfalfa EC fields, although the magnitude of the variations is still somewhat lower at the BREB site. 
Table 2. Midday averages of selected meteorological variables.

Average Temperature 1100-1500

\begin{tabular}{|c|c|c|c|c|c|c|}
\hline \multirow[b]{2}{*}{ Day } & \multicolumn{3}{|c|}{$\operatorname{Air}\left({ }^{\circ} \mathrm{C}\right)$} & \multicolumn{2}{|c|}{ Soil $\left({ }^{\circ} \mathrm{C}\right)$} & \multirow[b]{2}{*}{ W26 } \\
\hline & R8 & $\mathrm{P} 12$ & W26 & R8 & P12 & \\
\hline 157 & 26.2 & 24.6 & 22.8 & 56.4 & 20.2 & 17.5 \\
\hline 158 & 28.9 & 26.8 & 26.8 & 59.6 & 20.9 & $18 . C$ \\
\hline 159 & 27.8 & 24.3 & 24.5 & 48.6 & 16.7 & 17.7 \\
\hline 160 & 26.9 & 25.0 & 24.7 & 55.2 & 18.4 & 19.1 \\
\hline 161 & 26.1 & 24.0 & 23.7 & 53.5 & 17.3 & 19.4 \\
\hline 162 & 24.6 & 23.0 & 23.7 & 54.3 & 18.4 & 18.2 \\
\hline 163 & 28.5 & 27.1 & 26.5 & 52.6 & 17.5 & 17.4 \\
\hline 164 & 14.4 & M & 13.7 & 18.8 & M & 13.9 \\
\hline 165 & 20.3 & $M$ & 19.1 & 32.4 & $\mathrm{M}$ & 15.7 \\
\hline 166 & 20.3 & 19.6 & 19.4 & 36.6 & 15.7 & 16.5 \\
\hline
\end{tabular}

Average Wind and Humidity $1100-1500$

$\begin{array}{lcccccc}\text { Day } & \text { R8 } & \text { P12 } & \text { W26 } & \text { R8 } & \text { P12 } & \text { W26 } \\ 157 & 2.3 & 1.5 & 1.1 & 27 & 40 & 59 \\ 158 & 2.2 & 1.3 & 1.0 & 22 & 36 & 42 \\ 159 & 6.9 & 4.9 & 4.0 & 15 & 38 & 42 \\ 160 & 4.1 & 3.2 & 2.9 & 27 & 43 & 49 \\ 161 & 6.5 & 5.0 & 4.7 & 30 & 45 & 49 \\ 162 & 2.4 & 1.3 & 1.3 & 37 & 48 & 49 \\ 163 & 3.0 & 2.0 & 1.8 & 31 & 47 & 50 \\ 164 & 7.4 & \mathrm{M} & 6.2 & 82 & \mathrm{M} & 85 \\ 165 & 7.1 & \mathrm{M} & 5.6 & 41 & \mathrm{M} & 54 \\ 166 & 2.0 & 1.7 & 1.3 & 55 & 61 & 64\end{array}$

Average Radiation 1100-1500

Solar $\left(\mathrm{W} / \mathrm{m}^{2}\right)$

$\begin{array}{llll}\text { Day } & \text { R8 } & \text { P12 } & \text { W26 } \\ & & & \\ 157 & 909 & 883 & 881 \\ 158 & 926 & 902 & 895 \\ 159 & 834 & 809 & 816 \\ 160 & 937 & 911 & 924 \\ 161 & 910 & 887 & 901 \\ 162 & 754 & 732 & 741 \\ 163 & 840 & 814 & 790 \\ 164 & 276 & \text { M } & 280 \\ 165 & 864 & \text { M } & 828 \\ 166 & 818 & 903 & 811\end{array}$

$\operatorname{Net}\left(\mathrm{W} / \mathrm{m}^{2}\right)$

$\begin{array}{ll} & \mathrm{P} 12 \\ 480 & 562 \\ 478 & 574 \\ 452 & 513 \\ 499 & 565 \\ 510 & 558 \\ 383 & 439 \\ 451 & 520 \\ 171 & \mathrm{M} \\ 524 & \mathrm{M} \\ 481 & 542\end{array}$

Relative Humidity (\%)
18.0

17.7

19.1

19.4

18.2

17.4

15.7

6.5 
Table 3. Energy imbalance $\left(\mathrm{W} / \mathrm{m}^{2}\right)$ at EC sites during midday (1100 - $\left.1500 \mathrm{MDT}\right)$.

\begin{tabular}{ccc}
\hline Day & Potato Field 12 & Wheat Field 26 \\
157 & & +57 \\
158 & & +57 \\
159 & -97 & -96 \\
160 & -52 & -41 \\
161 & -76 & -58 \\
162 & +35 & +14 \\
163 & +57 & +36 \\
\hline
\end{tabular}

\section{Discussion of Flux Variability}

The unresolvable differences between the BREB and EC sites creates some uncertainty in the overall conclusions concerning flux variability. The EC $\mathrm{H}$ measurement will be assumed to be the most reliable, since there are no known fundamental problems with this measurement and the comparison between the EC sites indicates that they are comparable. Thus, a conservative approach is to estimate LE at the EC sites as a residual of net radiation, sensible heat flux, and soil heat flux. This can only be done directly at two sites, potato field 12 and wheat field 26 , where all these measurements were available. However, the EC data at other sites can still be used to make statements about the relative behavior of fluxes over the different types of fields.

Figure 14 shows the daily variation of fluxes over the different fields averaged over a 5-day period that includes both moderate and light wind days. Overall, latent heat flux is highest over wheat and alfalfa. Somewhat lower values are observed over potatoes and corn. The scatter plots had also suggested that corn and potatoes exhibit similar behavior while wheat and alfalfa are likewise similar to each other.

Figure 15 shows the variation of latent and sensible heat flux throughout the day as a function of wind speed. These curves are averages of three light wind and three moderate wind days and represent composites of all EC sites. Significant differences are observed between the light and moderate wind days. On moderate wind days latent heat flux is higher and sensible heat flux lower than on the light wind days. We hypothesize that this is caused by enhanced regional scale advection of sensible heat from the surrounding dry range land. Although some of the differences in observed latent heat flux may be due to errors associated with the EC computational approximation, we conclude that the differences are still large and significant since large differences of the opposite sign are observed in sensible heat flux. Although a similar wind speed dependence is not readily apparent in the BREB data, it should be noted that the smallest wind signal is observed over the EC corn site and thus the dependence may be obscured in the BREB data by uncertainties associated with the assumptions made in the BREB computations. 


\section{Comparison with BATS simulations.}

The Biosphere-Atmosphere Transfer Scheme (BATS) (Dickinson et al., 1987) was used to simulate the observed fluxes over potatoes and wheat. Experimental observations were used to specify the following variables in the model: air temperature above the canopy, incoming solar radiation, vapor pressure deficit, wind speed, and deep soil temperature. We also specified the vegetative cover at 1.0 for wheat and 0.5 for potatoes. The minimum stomatal resistance was set at $50 \mathrm{sm}^{-1}$. Soil moisture was set at near field capacity, and we specified a daily rain event (corresponding to the irrigation) of $10 \mathrm{~mm} / \mathrm{d}$. With these externally specified variables, the model internally calculates the temperatures of bare ground, leaves, and the air within the canopy. From these calculations, the model derives sensible and latent heat flux.

Figure 16 shows a comparison of latent and sensible heat flux from the BATS model compared to measurements over wheat. On most days, BATS provides somewhat lower estimates of latent heat flux by 10 to $30 \%$ at mid-day. Corresponding to this, sensible heat flux tends to be somewhat more positive (less negative) than the observations.

Figure 17 shows the results for potatoes. Model flux values are very similar to observed values. As with wheat, the model underestimates LE slightly, but the differences are not as large. Overall, BATS produces rather accurate estimates.

\section{References}

Avissar R., 1992: Conceptual aspects of a statistical dynamical approach to represent landscape subgrid-scale heterogeneities in atmospheric models. J. Geophys. Res., 97, 2729-2742.

Blad, B.L. and Rosenberg, N.J., 1974: Lysimetric calibration of the Bowen Ratio-Energy Balance method for evapotranspiration estimation in the central Great Plains. J. Appl. Meteorol., 13:227-236.

Claussen, M. 1991: Estimation of areally-averaged surface fluxes. Boundary-Layer Meteor., 54, $387-410$.

Doran, J.C., J.J. Barnes, R.L. Coulter, T.L. Crawford, D.D. Baldocchi, L. Balick, D.R. Cook, D. Cooper, R.J. Dobosy, W.A. Dugas, L. Fritschen, R.L.Hart, L. Hipps, J.M. Hubbe, W. Gao, R. Hicks, R.R. Kirkham, K.E. Kunkel, T.J. Martin, T.P. Meyers, W. Porch, J.D. Shannon, W.J. Shaw, E. Swiatek, and C.D. Whiteman, 1992: The Boardman Regional Flux Experiment. Bull. Amer. Meteor. Soc., 73, 1785-1795.

Dugas, W.A., 1992: Bowen ratio and eddy-flux measurements over three surfaces. Wetter and Leben, (In Press). 
Dugas, W.A., L.J. Fritschen, L.W. Gay, A.A. Held, A.D. Matthias, D.C. Reicosky, P. Steduto and J.L. Steiner, 1991: Bowen ratio, eddy correlation and portable chamber measurements over irrigated spring wheat. Agri. For Meteorol, 56:1-20.

Ohmura, A., 1982: Objective criteria for rejecting data for Bowen ratio flux calculations. J.Appl. Meteorol., 4:595-598.

Philip, J.R., 1961: The theory of heat flux meters. J. Geophys. Res., 66:571-579.

Rosenberg, N.J., and S.B. Verma, 1978: Extreme evaporation by irrigated alfalfa: A consequence of the 1976 Midwestern drought. J. Appl. Meteor., 17, 934-941.

Tanner, B.D., Greene, J.P. and Bingham, G.E., 1987: A Bowen ratio design for long term measurements. ASAE Tech. Paper No. 87-2503, ASAE, St. Joseph, MI.

Tanner, C.B., 1960: Energy balance approach to evapotranspiration from crops. Soil Sci. Soc. Am. Proc., 24:1-9.

Wyngaard, J.C., 1978: On surface-layer turbulence. In Workshop on Micrometeorology. American Meteorological Society, Boston, MA, pp. 109-149. 


\section{APPENDIX \\ EDDY CORRELATION COMPUTATIONAL PROCEDURES}

The Campbell Scientific, Inc. Krypton hygrometer (model KH20) was used for the measurement of latent heat flux and turbulent fluctuations of atmospheric water vapor. The voltage output $\mathrm{V}$ of the $\mathrm{KH} 20$ (an absorption device) is given by

$$
V=V_{o} e^{-k_{w} x p_{w}}
$$

where $V_{o}=$ base voltage, $k_{w}=$ water vapor absorption coefficient, $x=$ path separation between source and receiver, $\rho_{w}=$ water vapor density. Therefore

$$
\rho_{w}=\frac{1}{k_{w} x}\left(\ln V_{0}-\ln V\right)
$$

Using the eddy correlation technique, the latent heat flux (LE) is given by

$$
L E=L \overline{w^{\prime} \rho^{\prime}{ }_{w}}
$$

where $L=$ latent heat of vaporization, $w=$ vertical wind speed, and the prime indicates the fluctuating component of $w$ and $\rho_{w}$ about the mean. In the case of $\rho_{w}$

$$
\rho_{w}=\rho_{w}-\overline{\rho_{w}}=\frac{1}{k_{w} x}\left(\ln V_{o}-\ln V-\overline{\ln V_{o}}+\overline{\ln V}\right)
$$

Since $\mathrm{V}_{\mathrm{o}}$ is a constant, $\ln \mathrm{V}_{\mathrm{o}}=\ln \mathrm{V}_{\mathrm{o}}$, and

$$
\rho_{w}^{\prime}=\frac{1}{k_{w} x}(\overline{\ln V}-\ln V)
$$

CSI suggests the following approximation:

$$
\rho_{w}=-\frac{1}{k_{w} x} \frac{V^{\prime}}{\bar{V}}
$$


This can be derived in a number of ways. For instance, we note that

$$
\overline{\ln V} \approx \ln \bar{V}
$$

Therefore,

$$
\overline{\ln V}-\ln V \approx-\ln \frac{V}{\bar{V}}
$$

For situations where $\sigma_{\mathrm{v}} / \mathrm{V}$ is small, that is, the fluctuations in $\mathrm{V}\left(\rho_{\mathrm{w}}\right)$ are small compared to the mean, a series expansion can be used

$$
\ln \frac{V}{\bar{V}} \approx\left(\frac{V}{\bar{V}}-1\right)-\frac{1}{2}\left(\frac{V}{\bar{V}}-1\right)^{2}+\ldots
$$

Truncating at the first term gives

$$
\begin{gathered}
\ln \frac{V}{\bar{V}} \approx \frac{V}{\bar{V}}-1=\frac{V-\bar{V}}{\bar{V}}=\frac{V}{\bar{V}} \\
\rho_{w} \approx-\frac{1}{k_{w} x} \frac{V}{\bar{V}}
\end{gathered}
$$

Therefore

The experience of this investigator and others has been that energy balance closure is often not achieved using the CSI sonic anemometer/Krypton hygrometer. While measurement uncertainty virtually ensures that energy balance closure will often not be realized, it is nevertheless puzzling that the sum of latent, sensible, and soil heat fluxes is nearly always less than the net radiation (rather than randomly distributed about it).

The possible impact of the use of the approximate formula (eq. A.11) in estimating $\rho_{\mathrm{w}}{ }^{\prime}$ was evaluated. A CSI eddy correlation system was set up at the edge of an irrigated alfalfa field. The sonic anemometer, fine-wire thermocouple, and Krypton hydrometer were sampled at $10 \mathrm{~Hz}$ and stored in the SM192 storage module. No processing was done at this time. At that sampling rate, the SM192 can hold about 27 mins of data. When the module reached its capacity, data were downloaded to a PC, after which sampling was resumed. In all, 7 separate sampling periods were taken on two different days.

Latent heat flux was calculated using the two different approaches of calculating $\rho_{\mathrm{w}}^{\prime}$ (eq. A.5 and eq. A.11). Table A.1 compares the results. In all cases, the exact method produces higher flux 
values. On June 11 , the exact values are significantly higher, averaging $8 \%$. On June 13 , the differences are minor. The major difference between the two days is wind speed. On June 11, wind speeds were less than $2 \mathrm{~m} / \mathrm{s}$, while on June 13 , they were greater than $4 \mathrm{~m} / \mathrm{s}$.

Additional diagnostic analyses of this data set provides further insight. A 10-minute segment of data was extracted from the June 11 period 3 data set. The individual data points were separated into water vapor density fluctuation categories. Table A. 2 shows the percent of observations in each category, the average difference (approximate minus exact), and the contribution to the total latent heat flux using the exact and approximate equations. Key points are as follows:

1. Distribution of $\rho_{w}^{\prime}$ is asymmetric with a long tail on the positive side. The standard deviation of the time series is $1.4 \mathrm{gr} / \mathrm{m}^{3}$, though values occasionally exceed $+5 \mathrm{gr} / \mathrm{m}^{3}$.

2. Although deviations exceeding $+2 \mathrm{gr} / \mathrm{m}^{3}$ occur only about $10 \%$ of the time, they make a disproportionate contribution (47\%) to the total flux and account almost entirely for the latent heat flux error of about $10 \%$. This suggests that much of the flux is caused by infrequent, very moist upward plumes, a feature that has been observed by other investigators in light wind situations.

Figure A.1 through A. 7 show bar plots of the distribution of latent heat flux contributions as a function of $\rho_{\mathrm{w}}{ }^{\prime}$ for the seven tests illustrated in Table A.1. There is a direct relationship between the flux errors in Table A. 1 and the characteristics of the distributions indicated in the figures. The errors are larger when a larger contribution is made at large positive values of $\rho_{w}{ }^{\prime}$. On the moderate wind day (June 13), a large percentage of the flux occurs at smaller absolute values of $\rho_{w}^{\prime}$, and therefore the errors are smaller.

It is not clear how often the approximate method would cause significant flux errors. Clearly, these data were taken under rather extreme conditions. In humid regions, errors may be negligible. However, during period when latent heat flux is high, wind speeds are low and for experiments conducted in arid regions where irrigation is supplying water, it would appear that the approximate methods suggested by CSI can lead to significant systematic underestimates of latent heat flux. The exact method should be used instead.

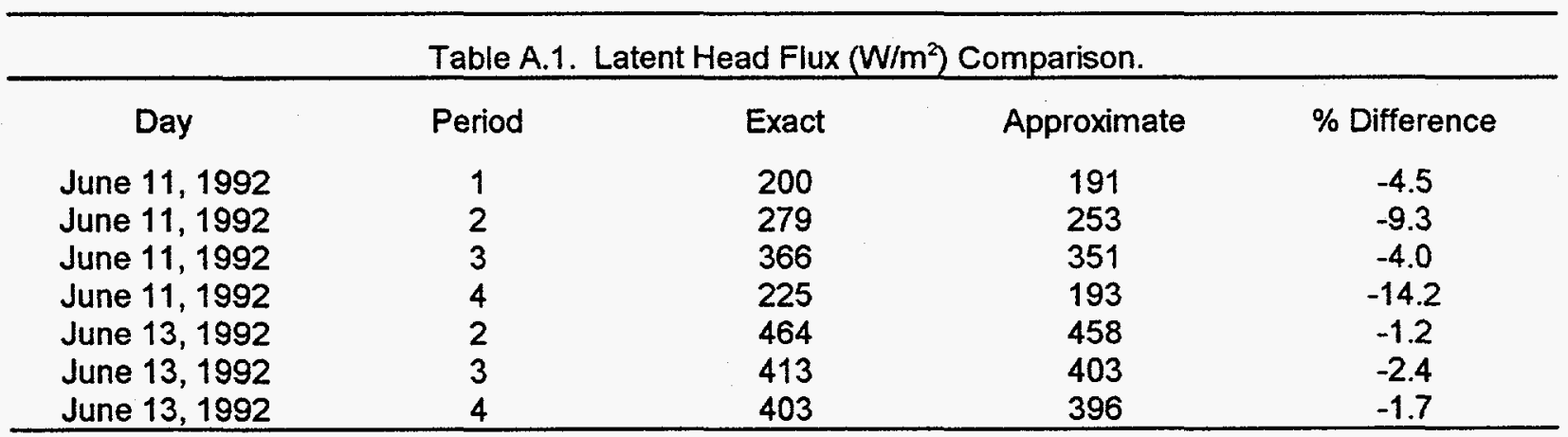


Table A.2. Distribution of $\rho_{w}^{\prime}$ and latent heat flux for a 10-minute period on June 11, 1992.

\begin{tabular}{ccccc}
$\rho_{\mathrm{w}}^{\prime}\left(\mathrm{gr} / \mathrm{m}^{3}\right)$ & \% Obs. & Difference $\left(\mathrm{gr} / \mathrm{m}^{3}\right)$ & LE (exact) & LE (approx.) \\
-2.5 to -2.0 & 0.05 & -0.16 & 0.6 & 0.7 \\
-2.0 to -1.5 & 4.2 & -0.05 & 23.0 & 23.7 \\
-1.5 to 1.0 & 25.3 & 0.04 & 97.9 & 94.3 \\
-1.0 to -0.5 & 18.1 & 0.13 & 7.8 & 7.2 \\
-0.5 to 0 & 14.2 & 0.13 & 2.6 & 1.6 \\
0 to 0.5 & 9.3 & 0.12 & 2.1 & 2.9 \\
0.5 to 1.0 & 7.9 & 0.08 & 14.7 & 16.3 \\
1.0 to 1.5 & 5.6 & 0.00 & 21.8 & 21.8 \\
1.5 to 2.0 & 4.2 & -0.11 & 22.7 & 21.4 \\
2.0 to 2.5 & 3.3 & -0.25 & 27.9 & 24.9 \\
2.5 to 3.0 & 3.4 & -0.40 & 46.4 & 39.5 \\
3.0 to 3.5 & 2.0 & -0.59 & 35.6 & 29.1 \\
3.5 to 4.0 & 0.9 & -0.79 & 17.2 & 13.6 \\
4.0 to 4.5 & 0.9 & -1.04 & 21.1 & 15.9 \\
4.5 to 5.0 & 0.5 & -1.27 & 17.0 & 12.4 \\
5.0 to 5.5 & 0.1 & -1.47 & 3.8 & 2.7 \\
& & & Total & 362.4 \\
\hline
\end{tabular}




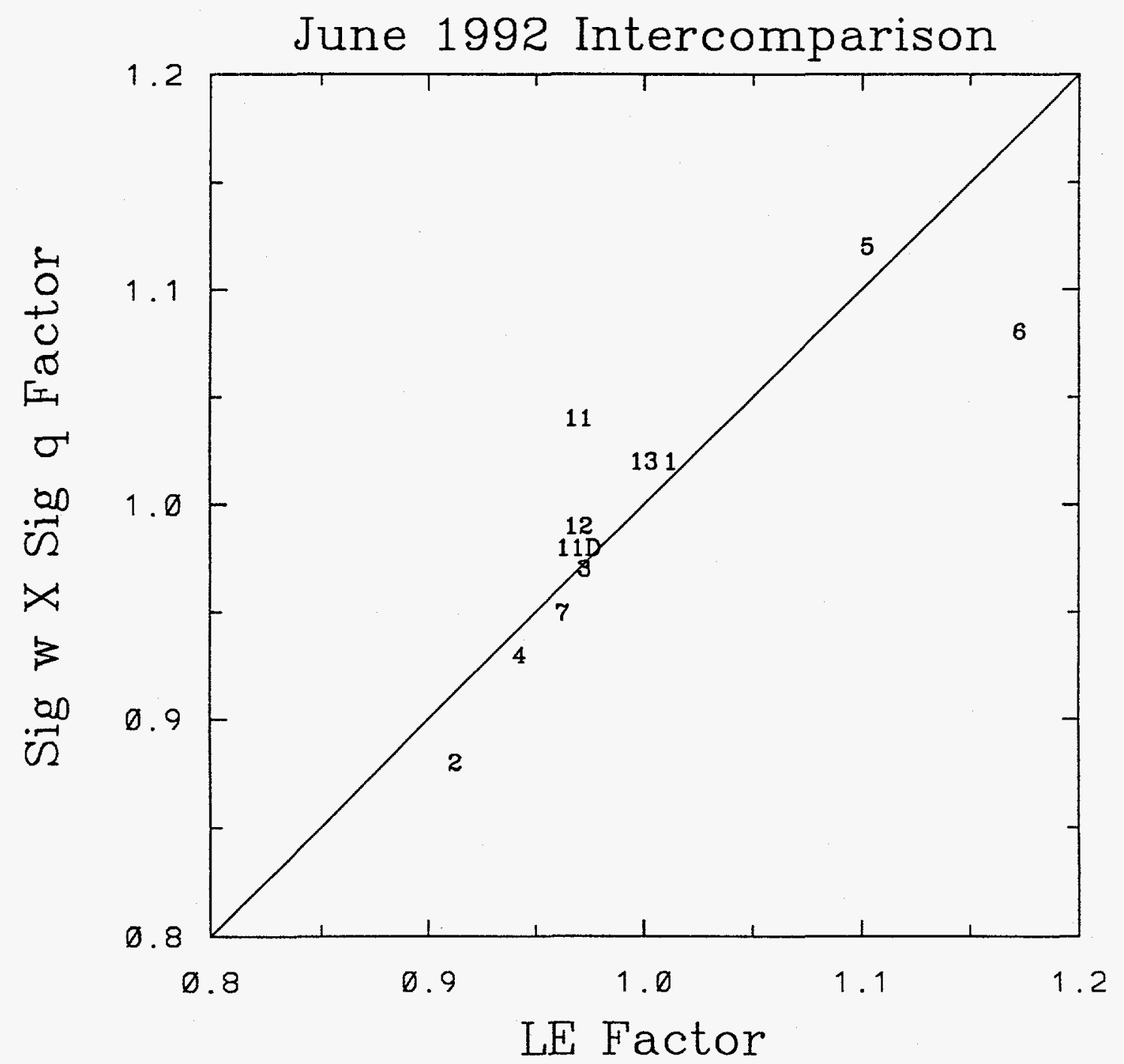

Figure 1. LE adjustment factors derived from a direct comparison of LE data vs. LE adjustment factors derived from a comparison of $\sigma \mathrm{w}$ and $\sigma \mathrm{q}$ data. Numbers on the graph are the station identifiers. Stations 8-10 did not measure LE and are not represented on this graph. 

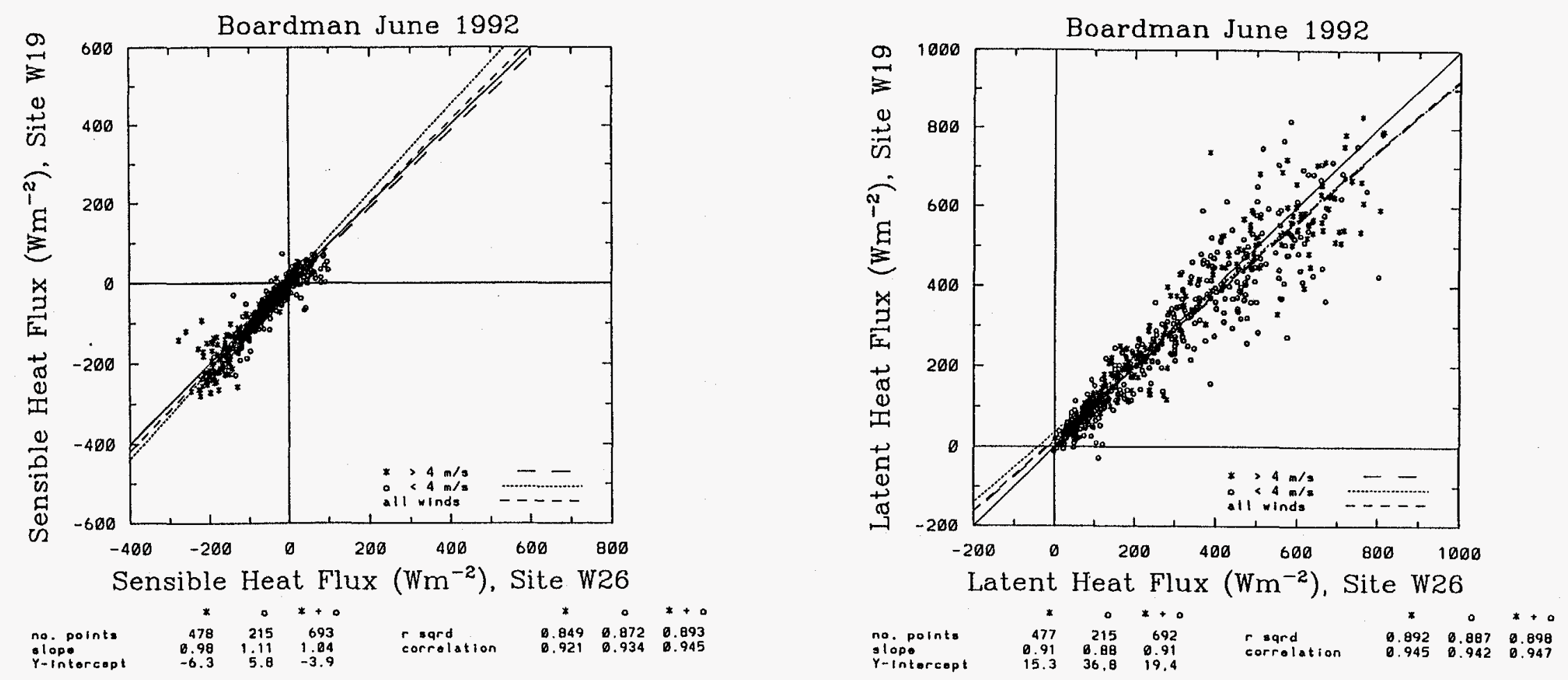

Figure 2. Comparison of sensible and latent heat fluxes between wheat field 26 and wheat field 19. Each point represents a 15 -minute average. The solid diagonal line is a 1:1 line. The other diagonal lines represent linear least squares fit to all the data or subsets of the data based on wind speed as denoted in the graph. 


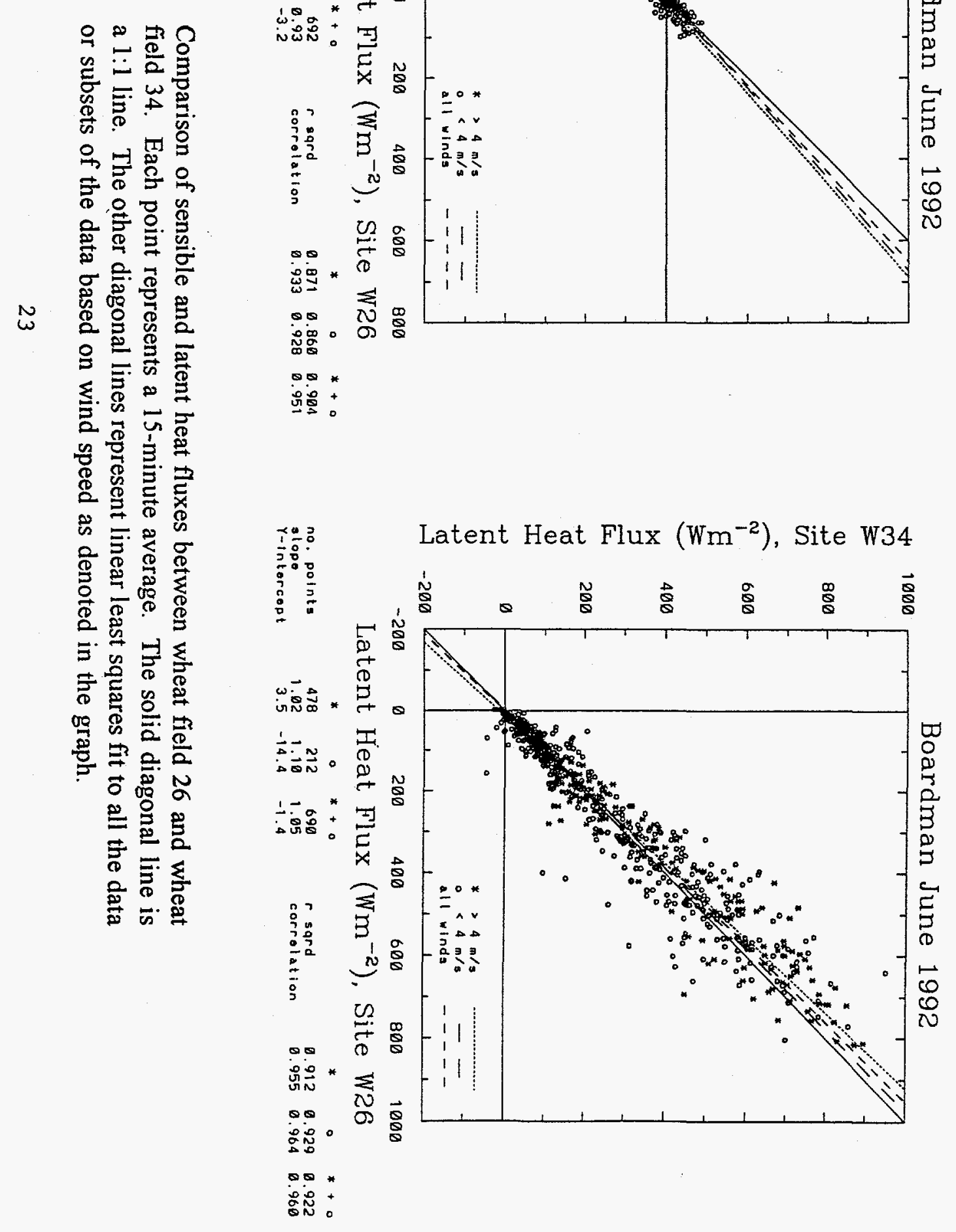



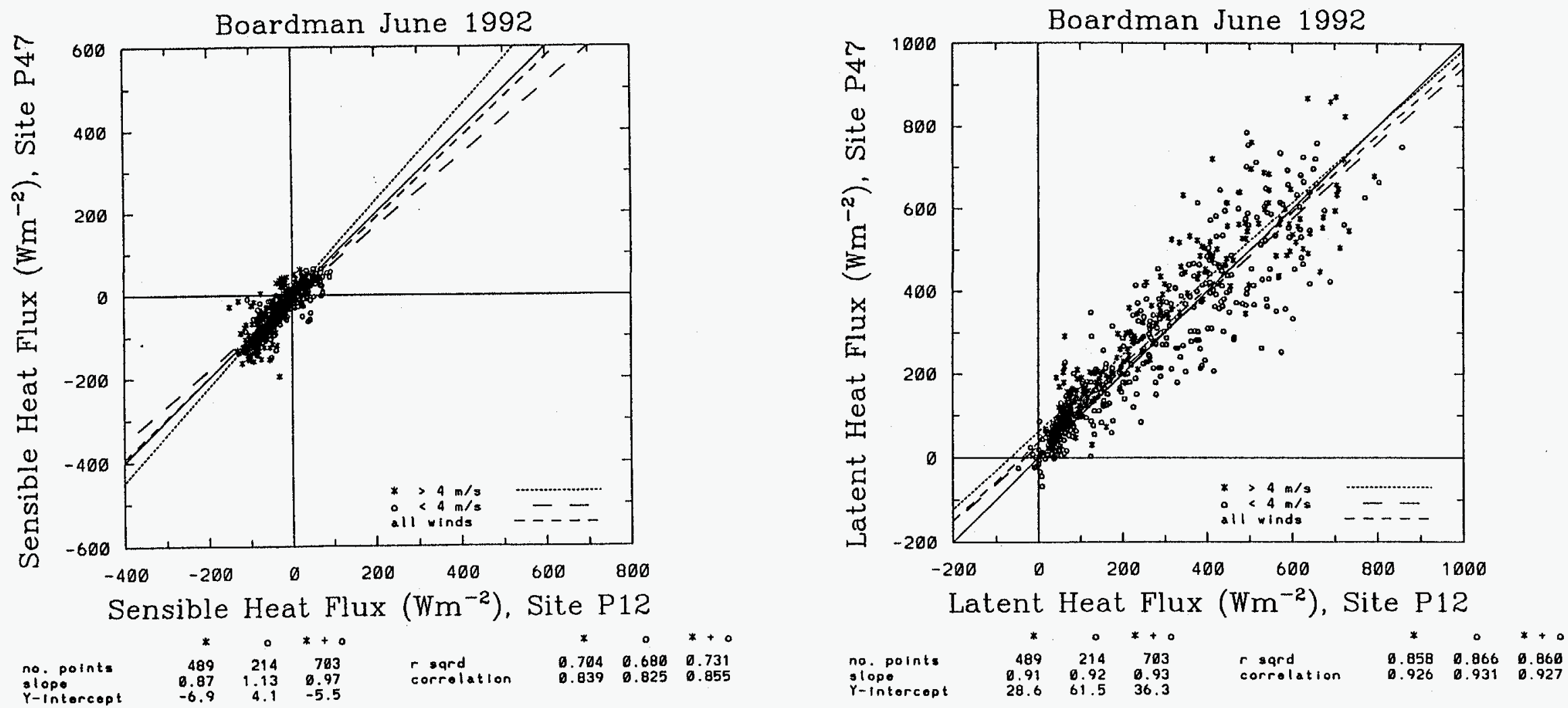

Figure 4. Comparison of sensible and latent heat fluxes between potato field 12 and potato field 47. Each point represents a 15-minute average. The solid diagonal line is a 1:1 line. The other diagonal lines represent linear least squares fit to all the data or subsets of the data based on wind speed as denoted in the graph. 

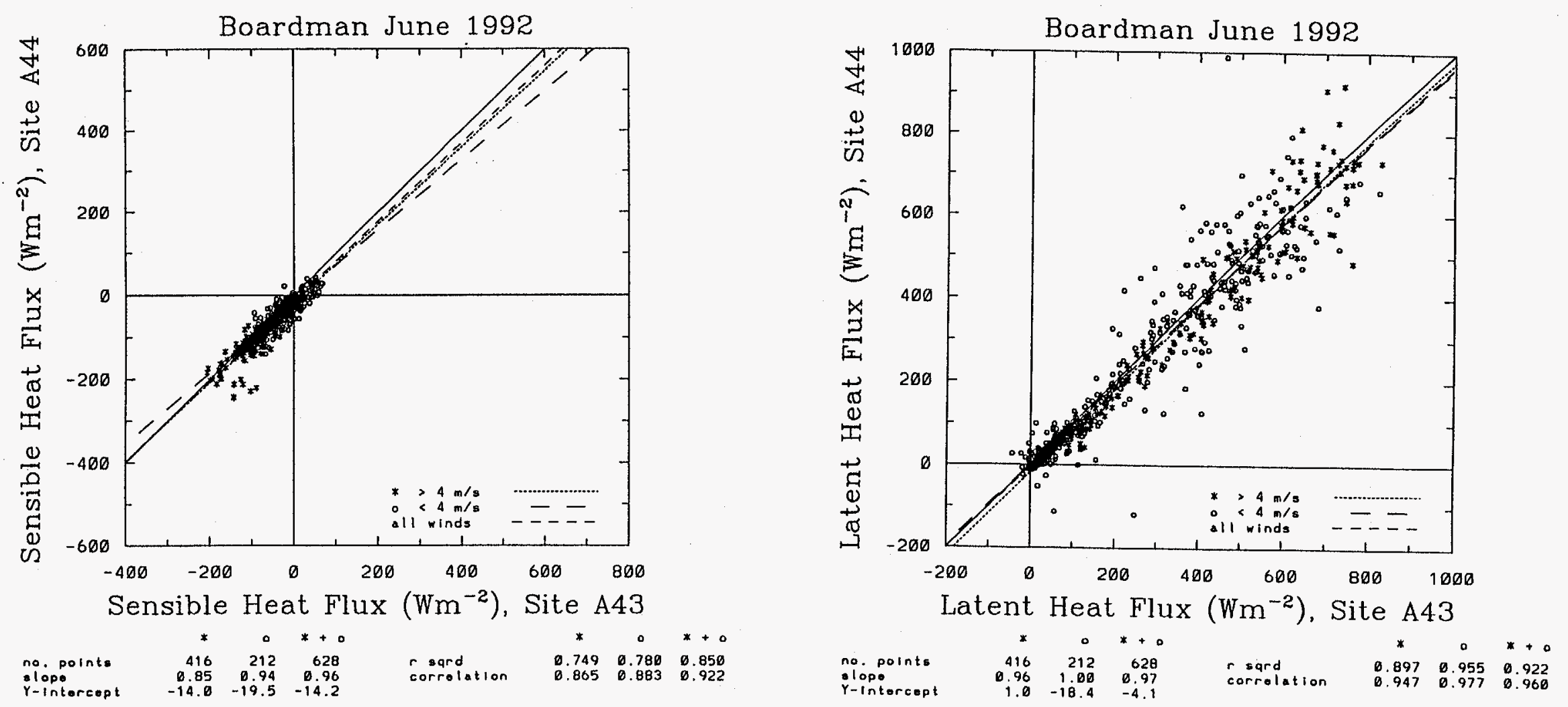

Figure 5. Comparison of sensible and latent heat fluxes between alfalfa field 43 and alfalfa field 44. Each point represents a 15 -minute average. The solid diagonal line is a 1:1 line. The other diagonal lines represent linear least squares fit to all the data or subsets of the data based on wind speed as denoted in the graph. 

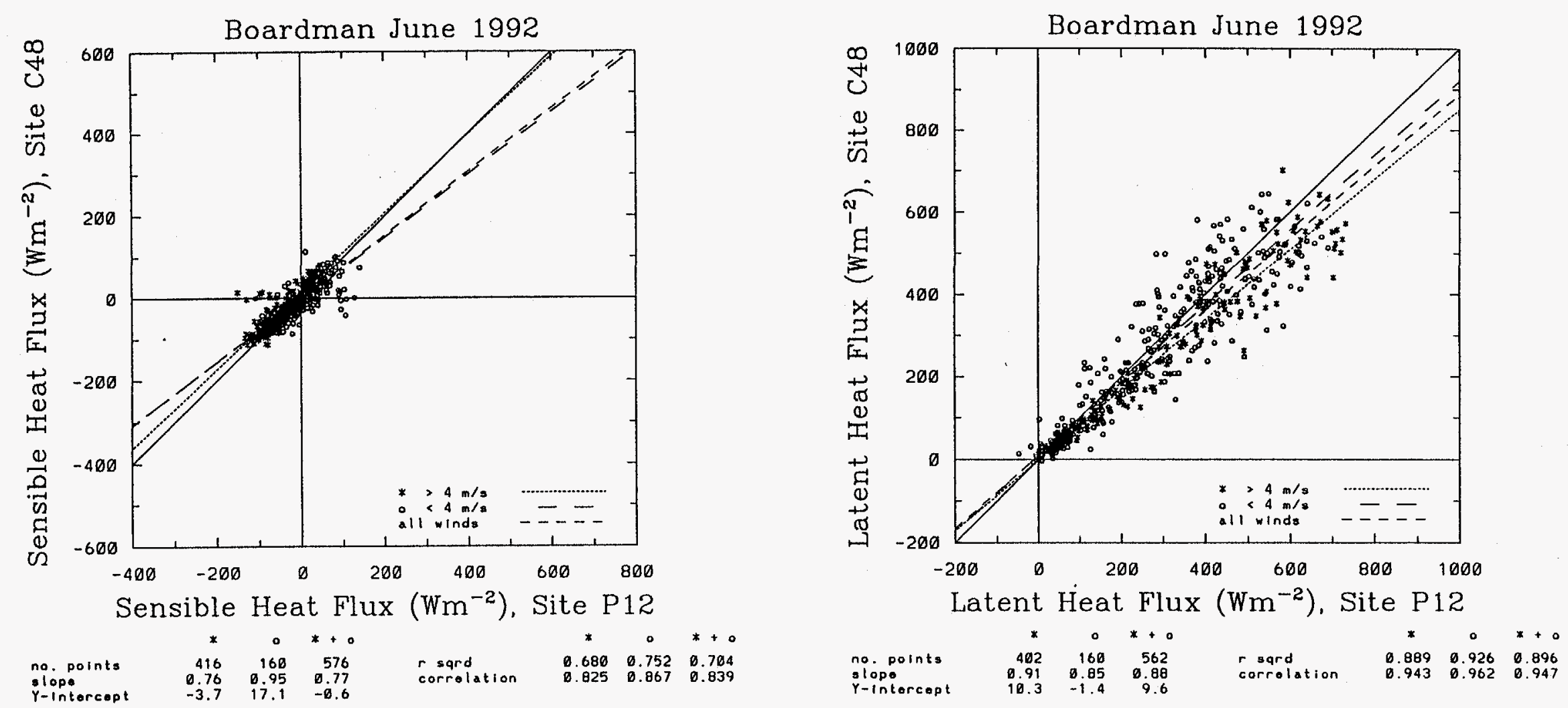

Figure 6. Comparison of sensible and latent heat fluxes between potato field 12 and corn field 48. Each point represents a 15 -minute average. The solid diagonal line is a $1: 1$ line. The other diagonal lines represent linear least squares fit to all the data or subsets of the data based on wind speed as denoted in the graph. 


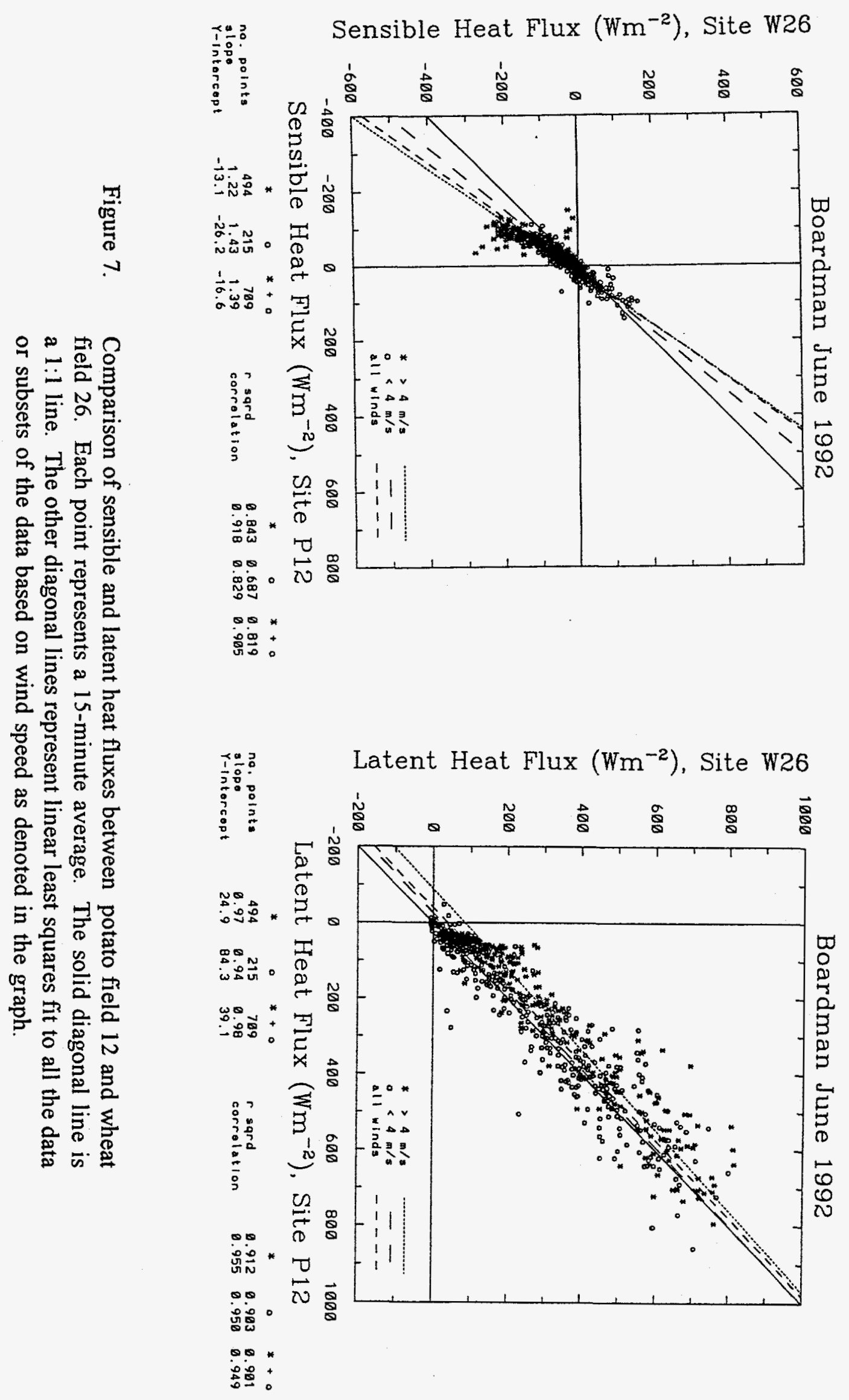



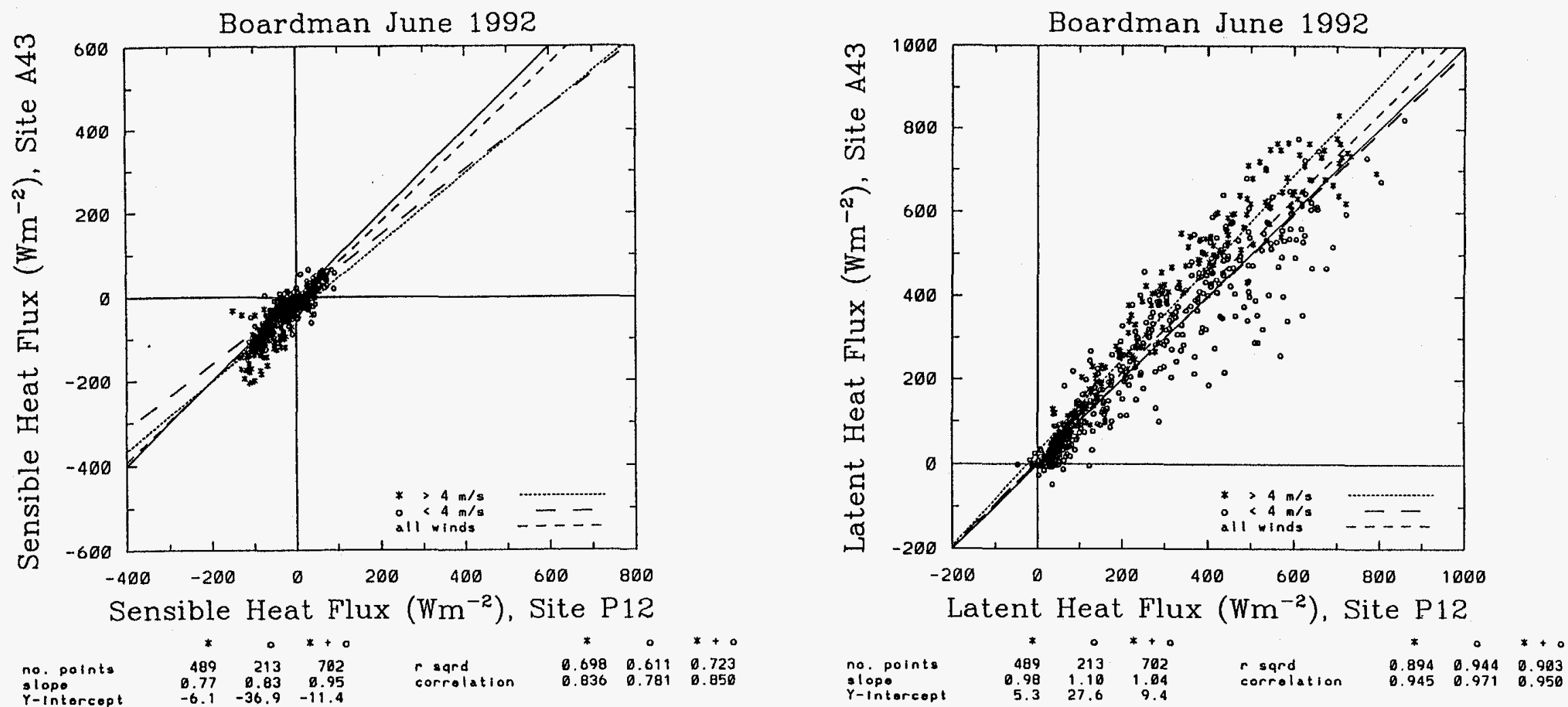

Figure 8. Comparison of sensible and latent heat fluxes between potato field 12 and alfalfa field 43. Each point represents a 15-minute average. The solid diagonal line is a 1:1 line. The other diagonal lines represent linear least squares fit to all the data or subsets of the data based on wind speed as denoted in the graph. 

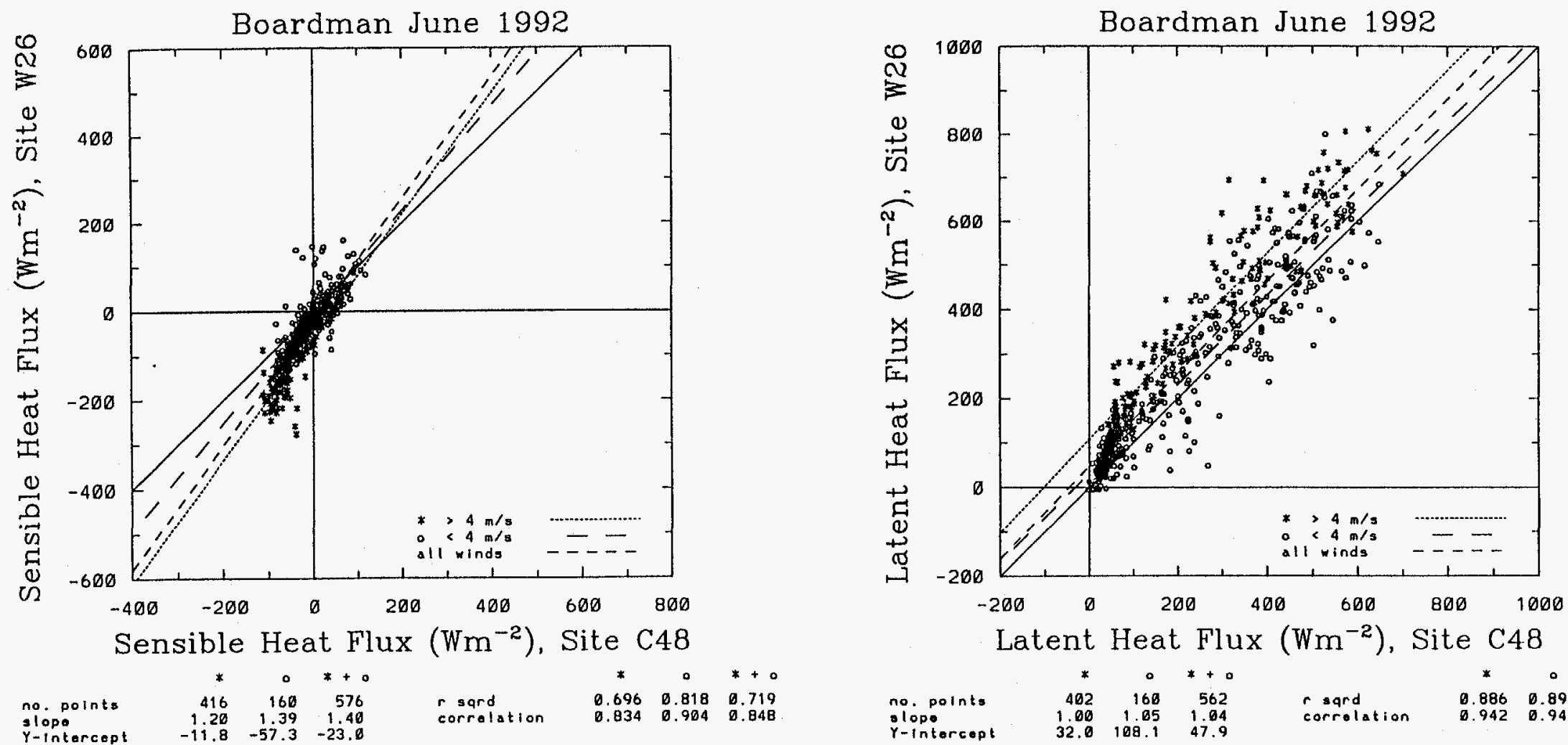

Figure 9. Comparison of sensible and latent heat fluxes between corn field 48 and wheat field 26. Each point represents a 15 -minute average. The solid diagonal line is a 1:1 line. The other diagonal lines represent linear least squares fit to all the data or subsets of the data based on wind speed as denoted in the graph. 
Sensible Heat Flux $\left(\mathrm{Wm}^{-2}\right)$, Site $\mathrm{A} 43$

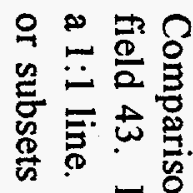

$\frac{3}{0}$

웅버용 훙후웅

- 웅

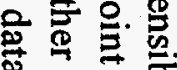

응 $\frac{7}{5}$

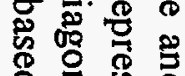

2.

震票

छ.

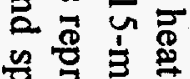

究实

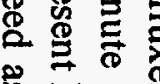

兵

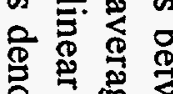

宽离

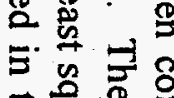

호율

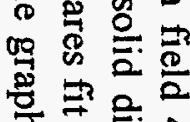

응

ڤ气

झ

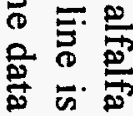

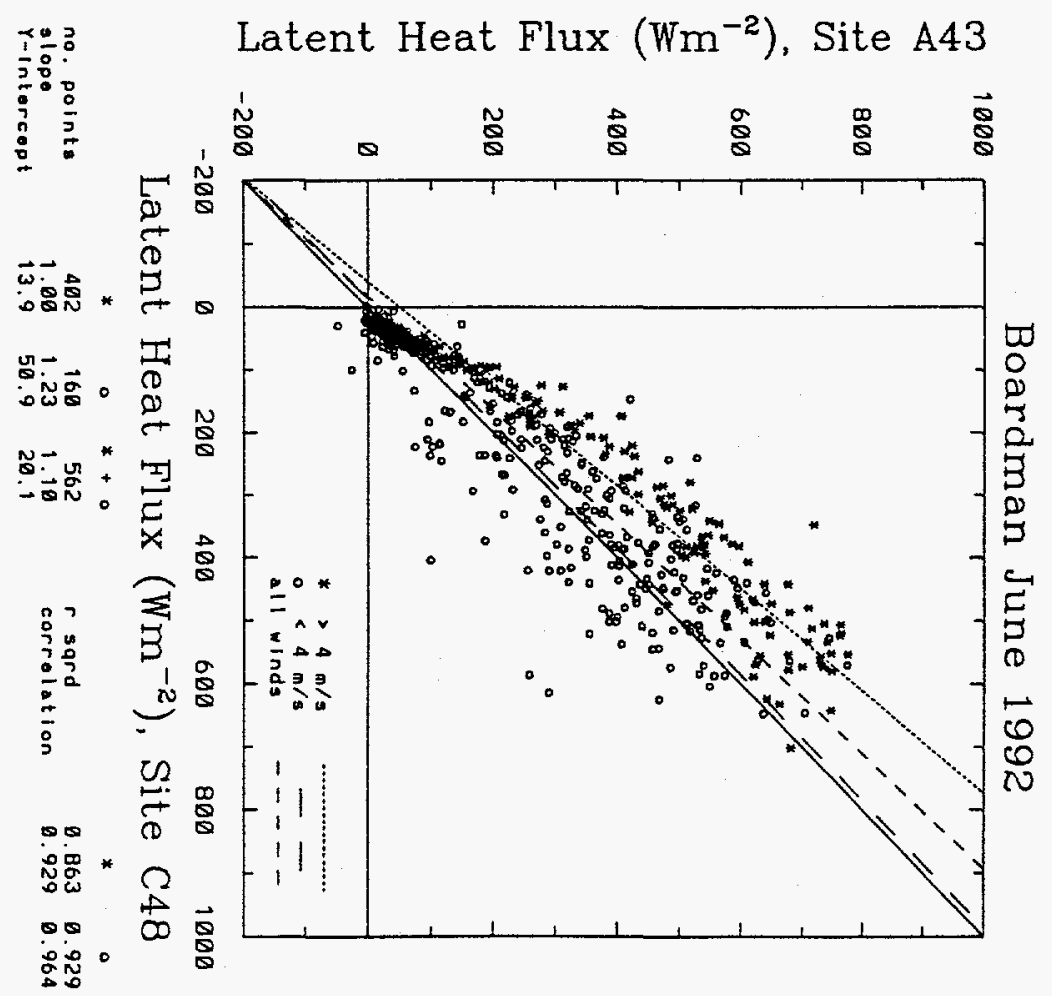



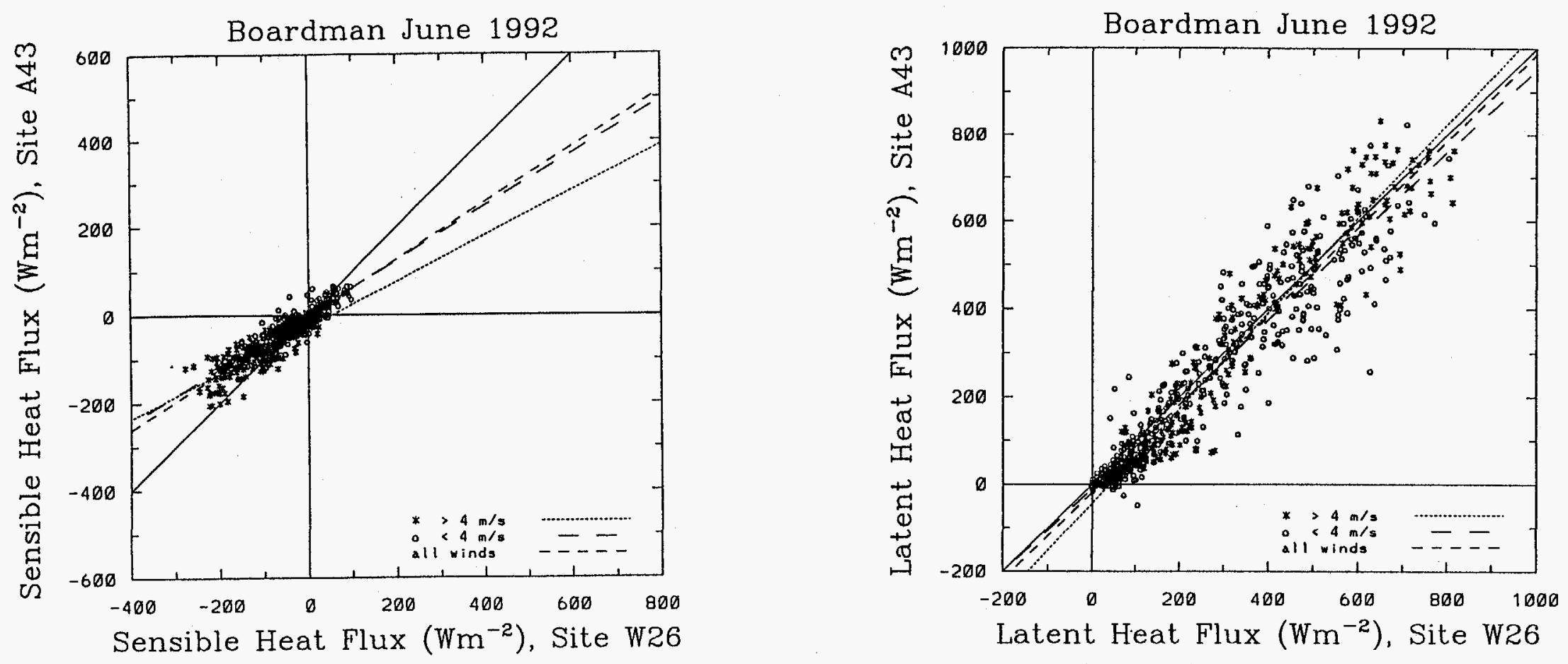

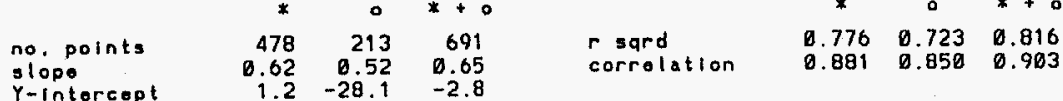

$\begin{array}{lrrrlrrr} & * & 0 & *+0 & & * & * & * \\ \text { no.peints } & 478 & 213 & 691 & \text { r sard } & 0.895 & 0.909 & 0.904 \\ \text { slopo } & 0.96 & 1.08 & 1.00 & \text { corrolation } & 0.946 & 0.954 & 0.951\end{array}$

Figure 11. Comparison of sensible and latent heat fluxes between wheat field 26 and alfalfa field 43. Each point represents a 15-minute average. The solid diagonal line is a 1:1 line. The other diagonal lines represent linear least squares fit to all the data or subsets of the data based on wind speed as denoted in the graph. 


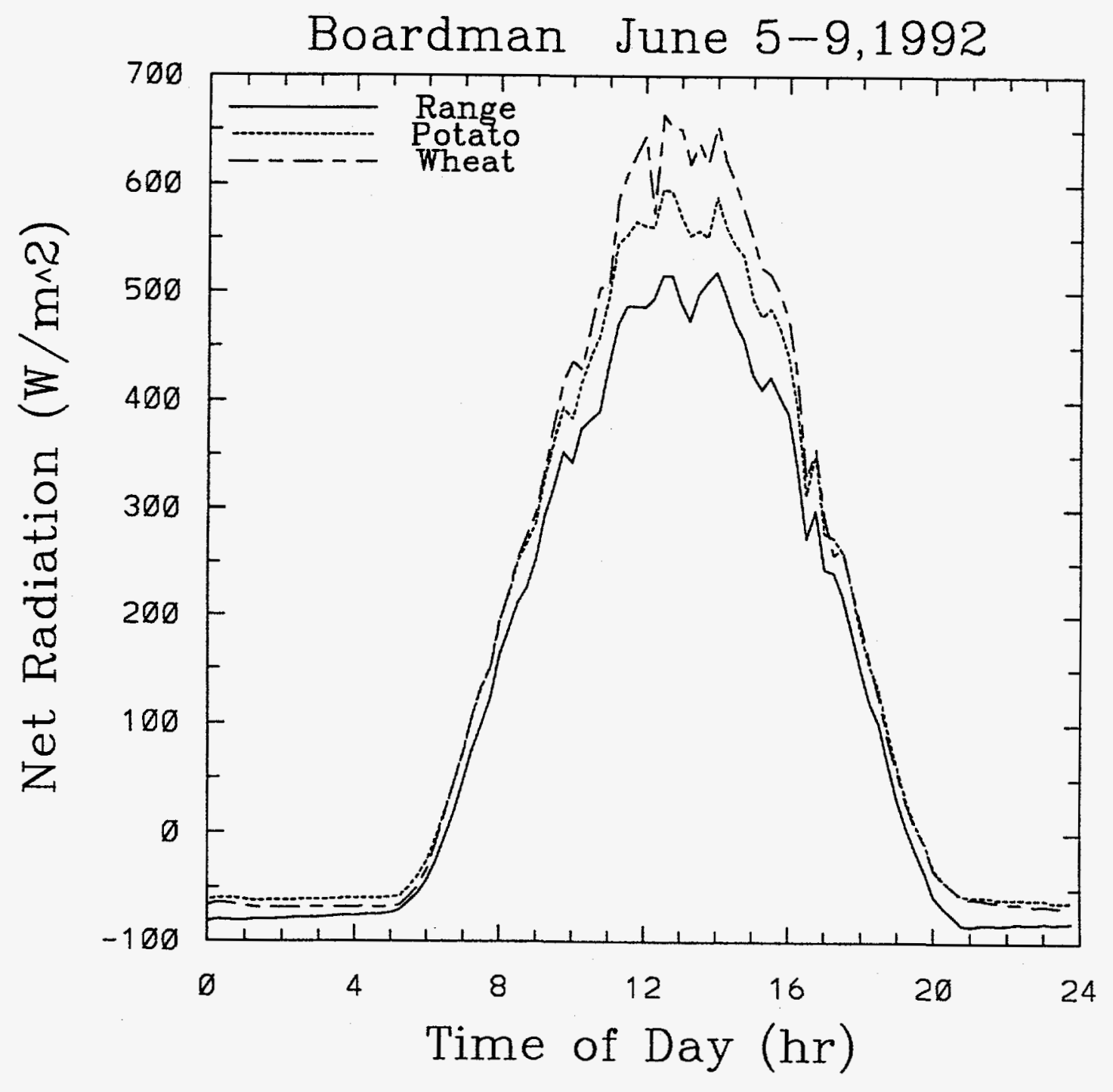

Figure 12. Average diurnal variation of net radiation for a range of site 8 , potato field 12 , and wheat field 26 during June 5-9, 1992. 


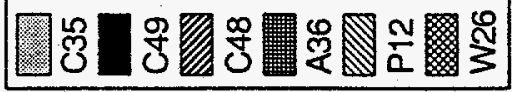
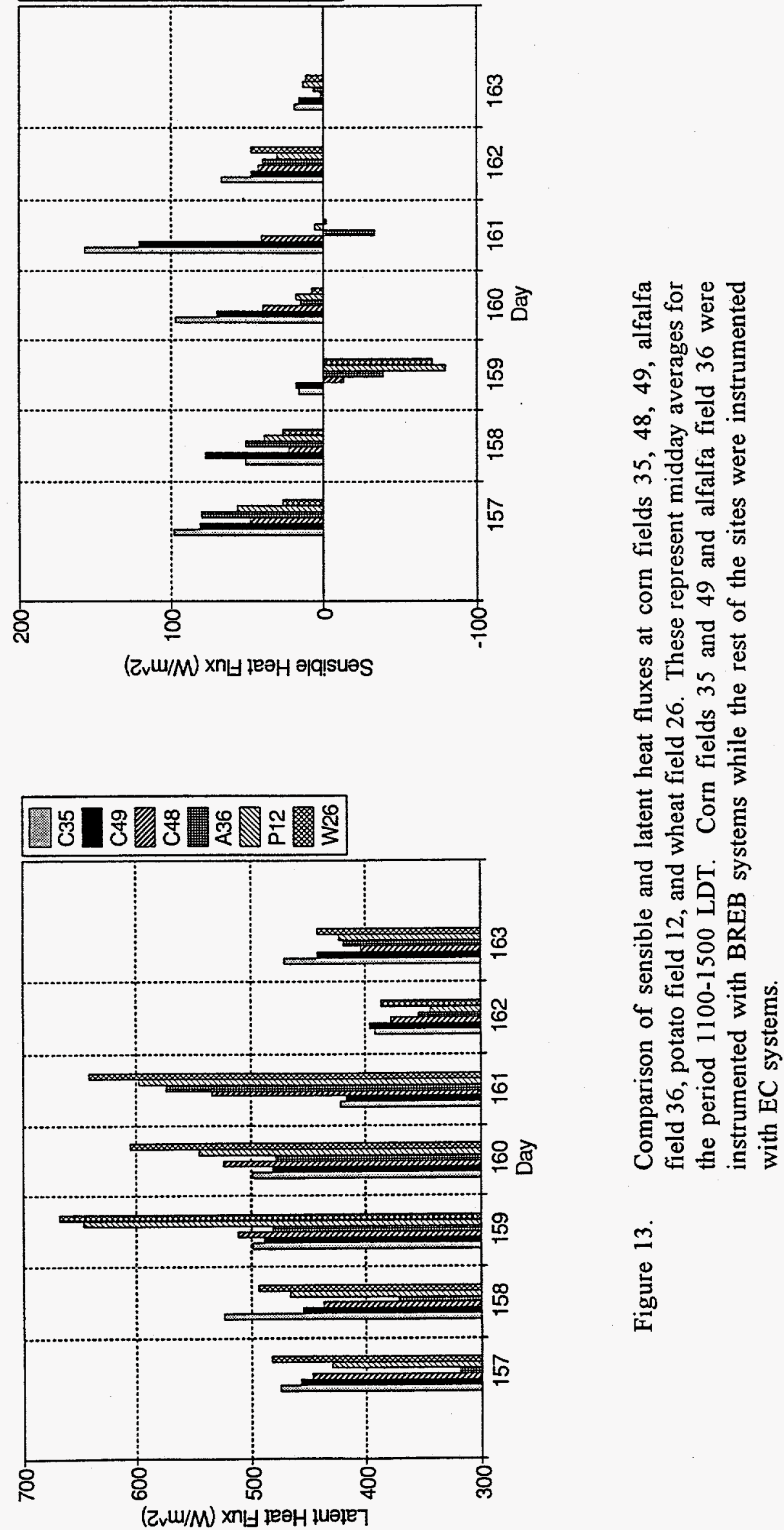

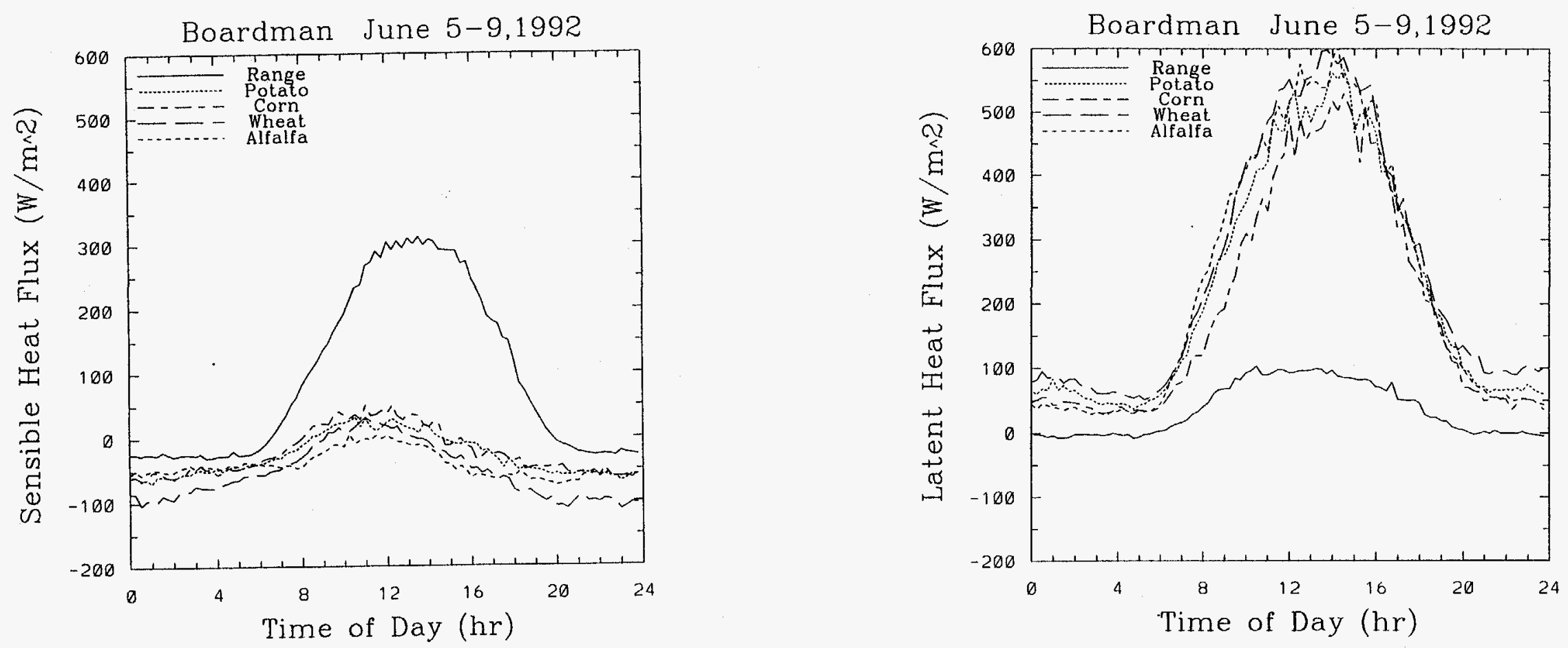

Figure 14. Diurnal variation of sensible and latent heat fluxes over the different surface types for the period June 5-9, 1992. The curves represent averages of all of the EC sites. 


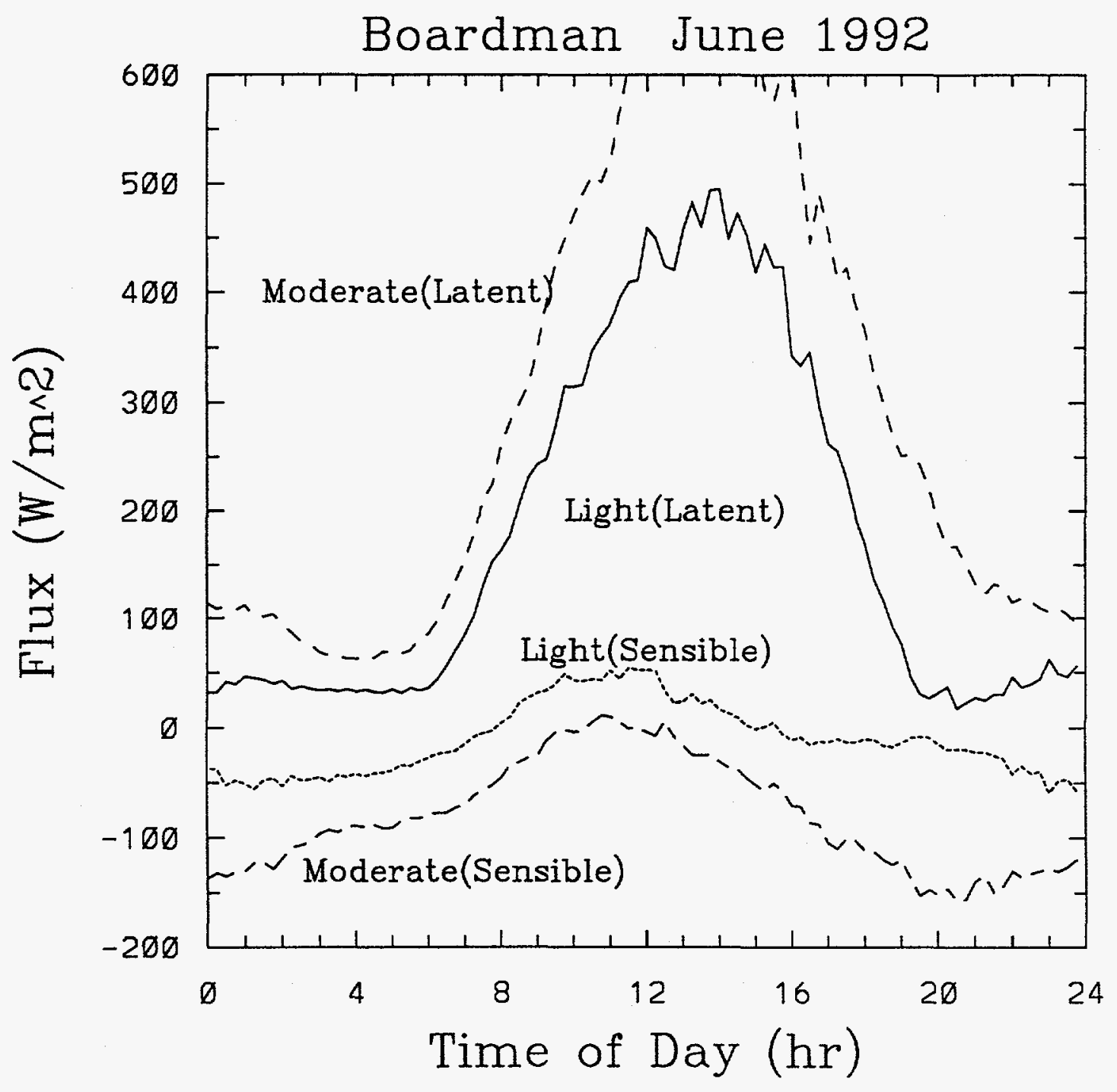

Figure 15. Diurnal variation of sensible and latent heat fluxes as a function of wind speed. The curves denoted as "moderate" are averages of days 159,160, and 161. The curves denoted "light" represent averages of days 157, 158, and 162. These are averages of all farm EC sites. 


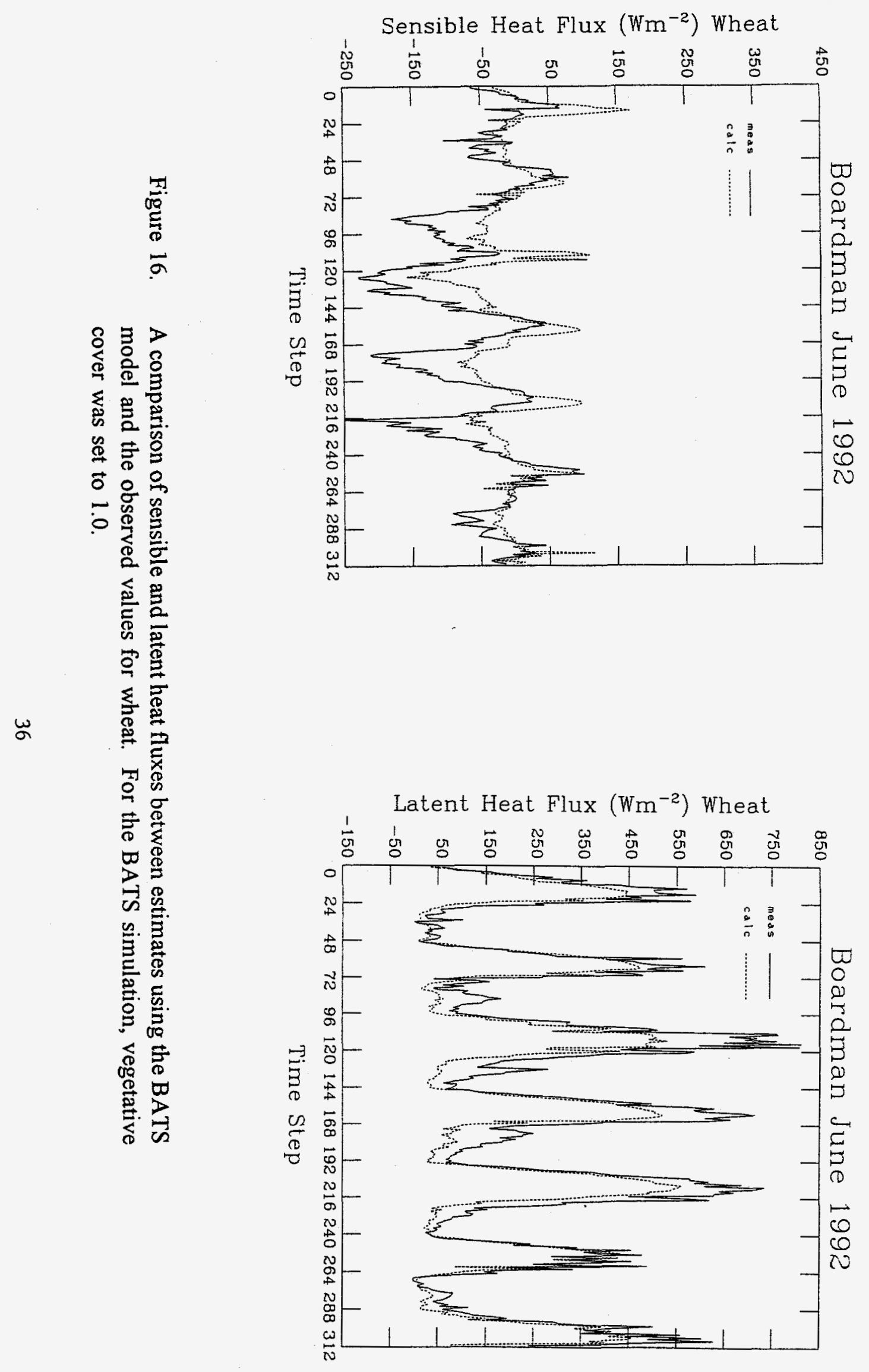




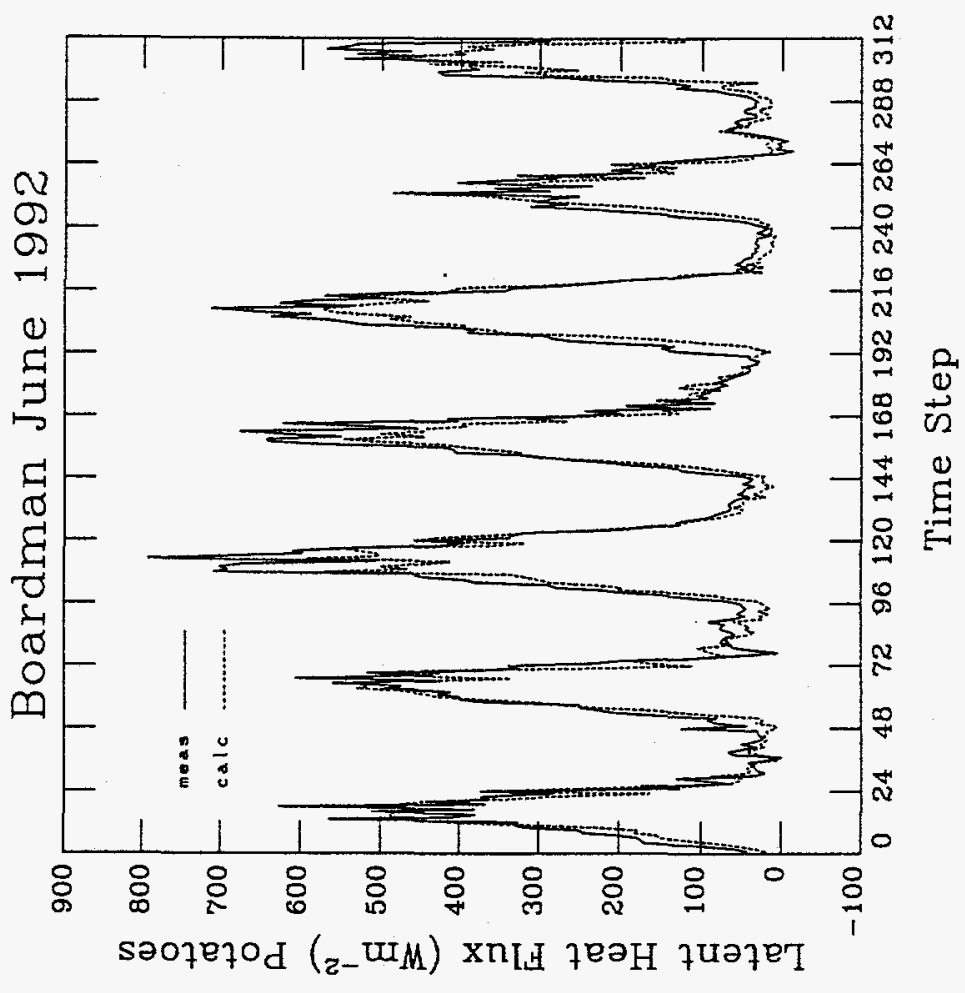

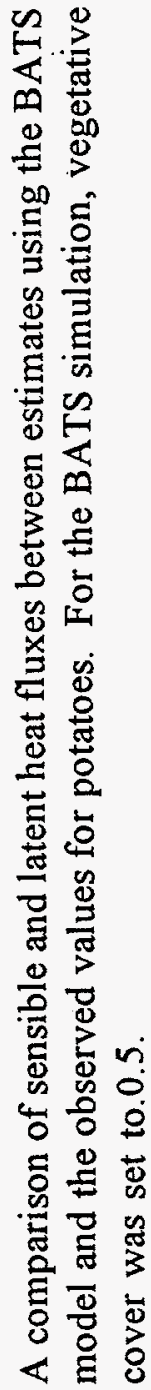

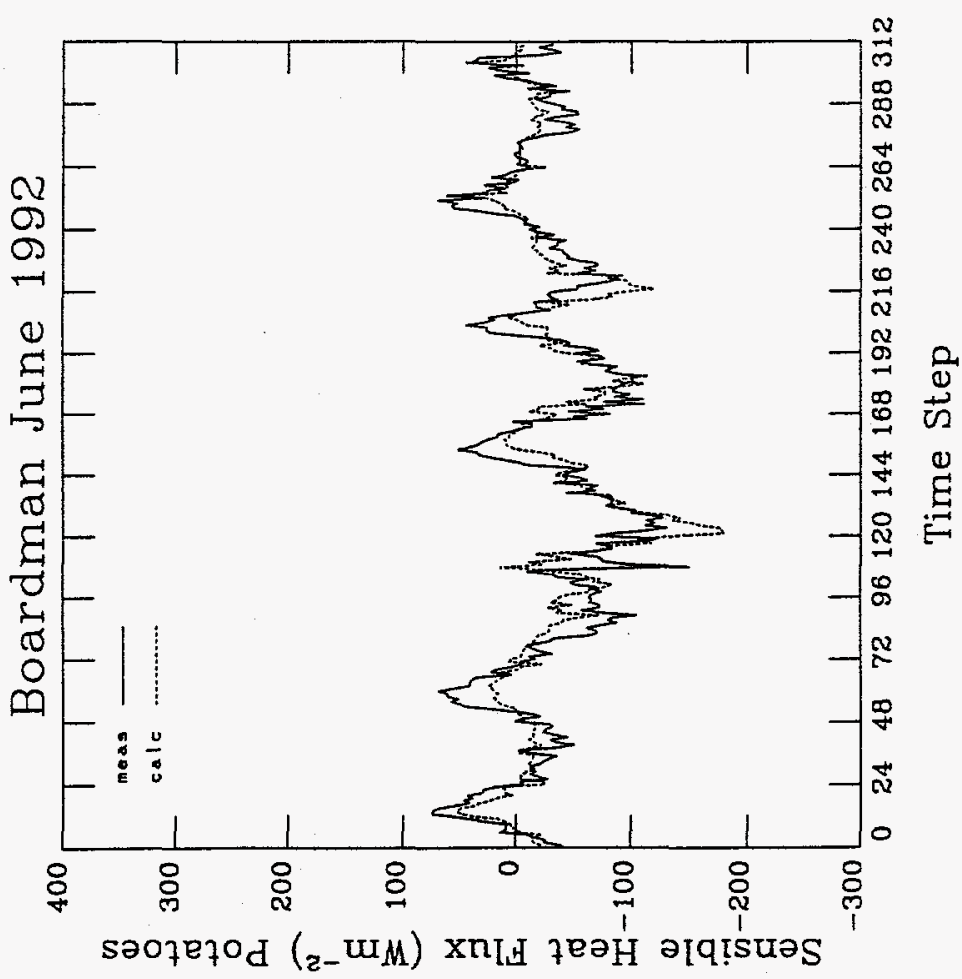

立 


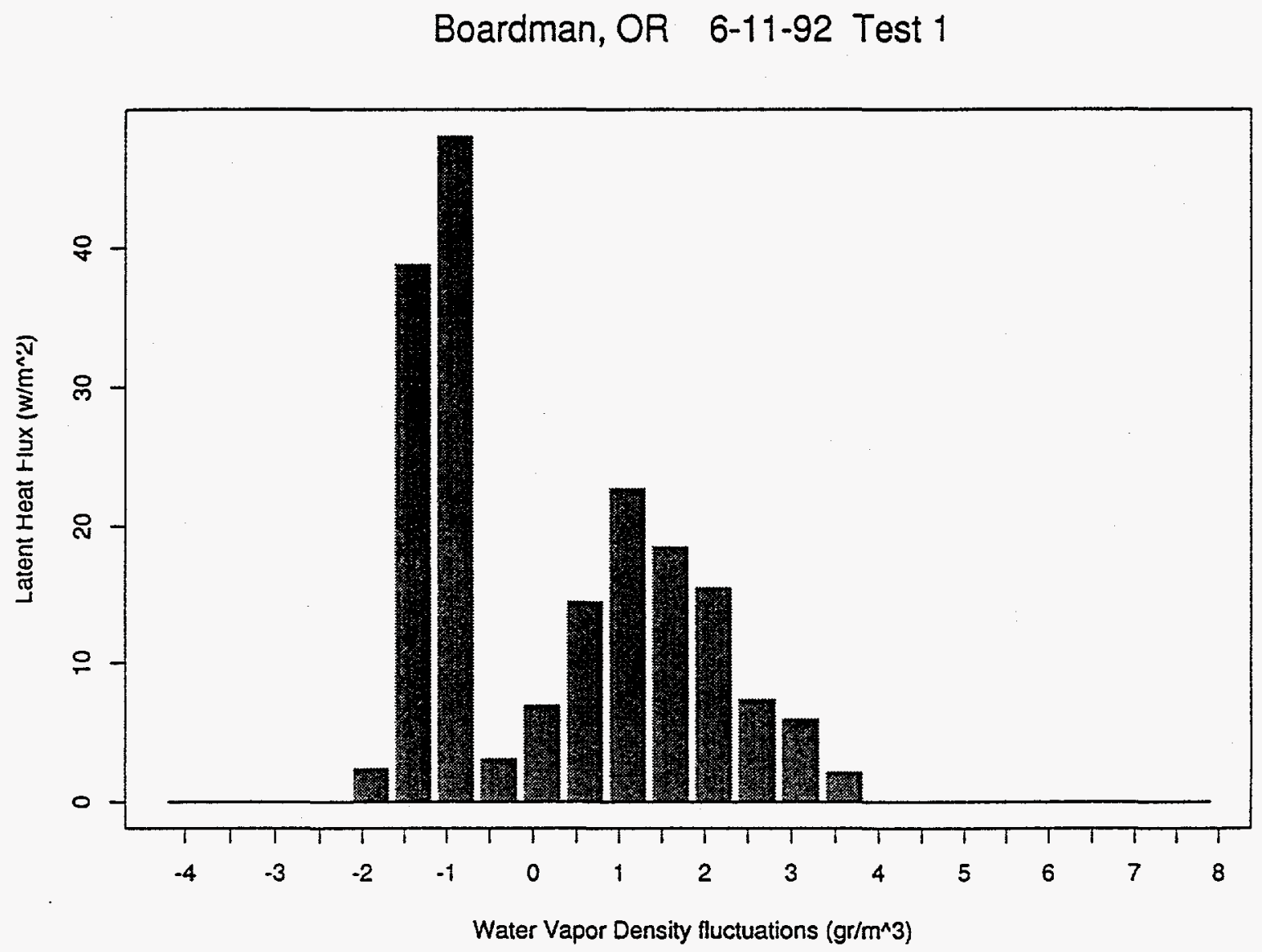

Figure A.1. Contribution to the total latent heat flux categorized by water vapor density fluctuations from the mean, for a 27 -minute period on June 11 . 


\section{Boardman, OR 6-11-92 Test 2}

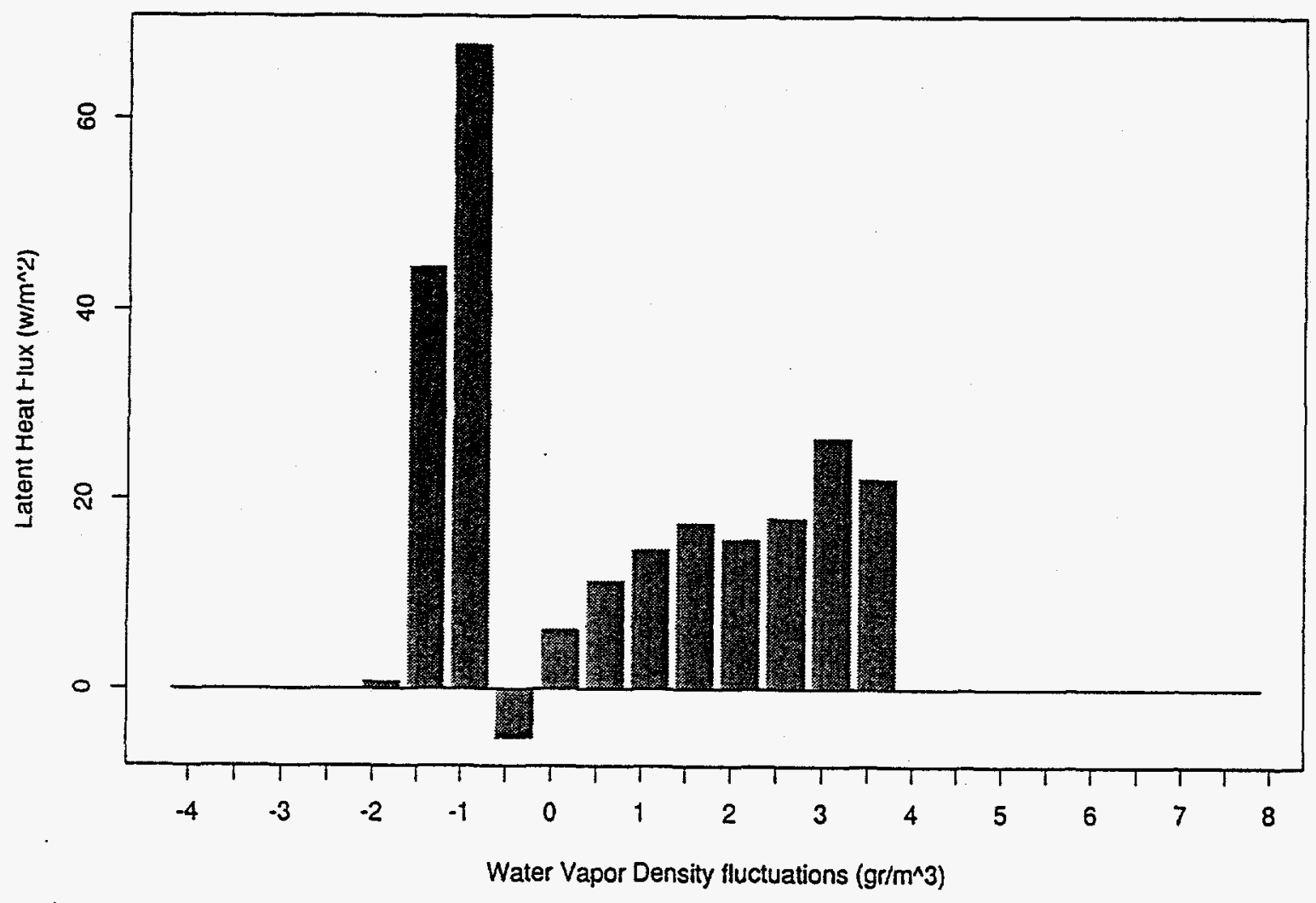

Figure A.2. Contribution to the total latent heat flux categorized by water vapor density fluctuations from the mean, for a 27 -minute period on June 11 . 


\section{Boardman, OR 6-11-92 Test 3}

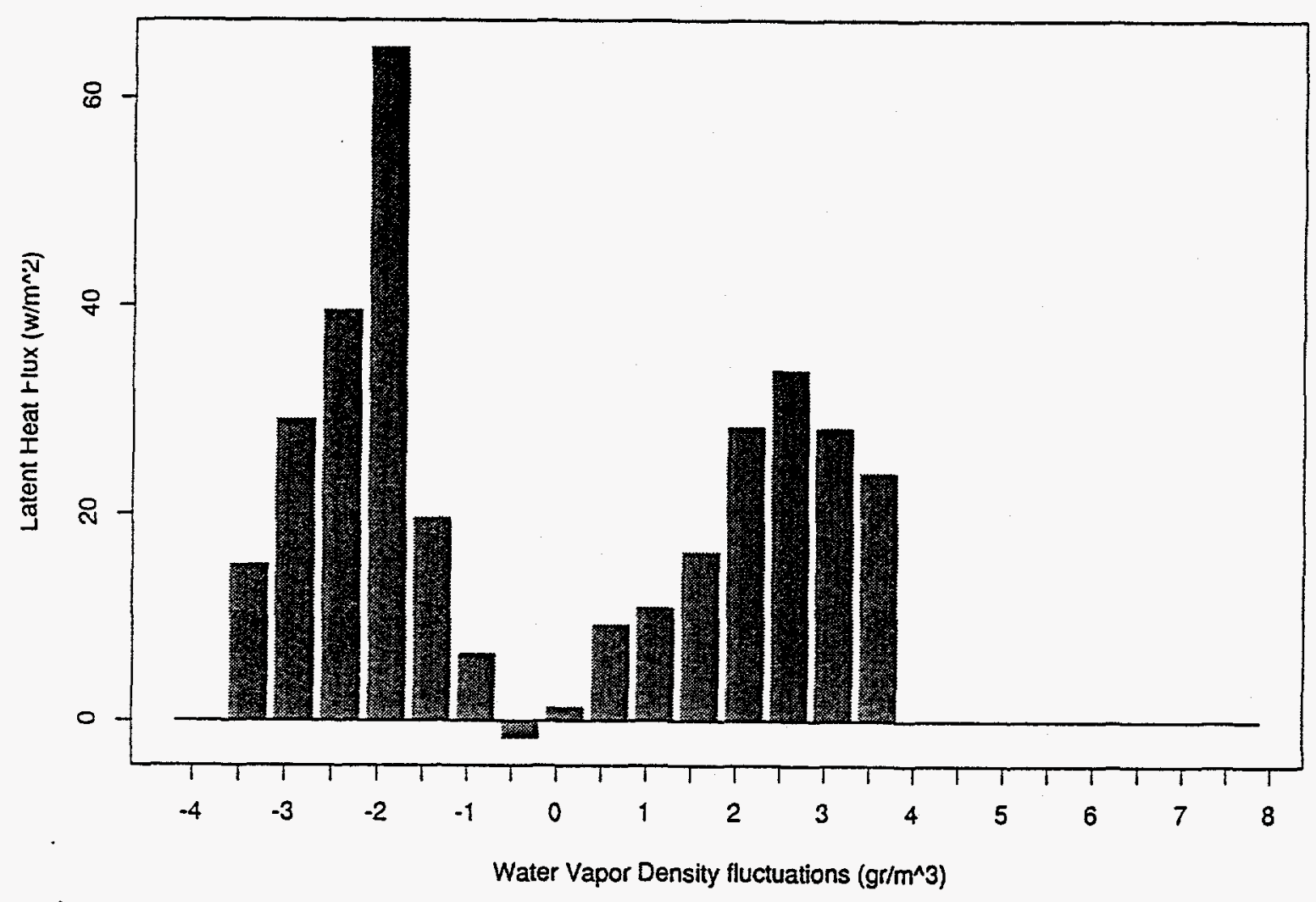

Figure A.3. Contribution to the total latent heat flux categorized by water vapor density fluctuations from the mean, for a 27 -minute period on June 11 . 


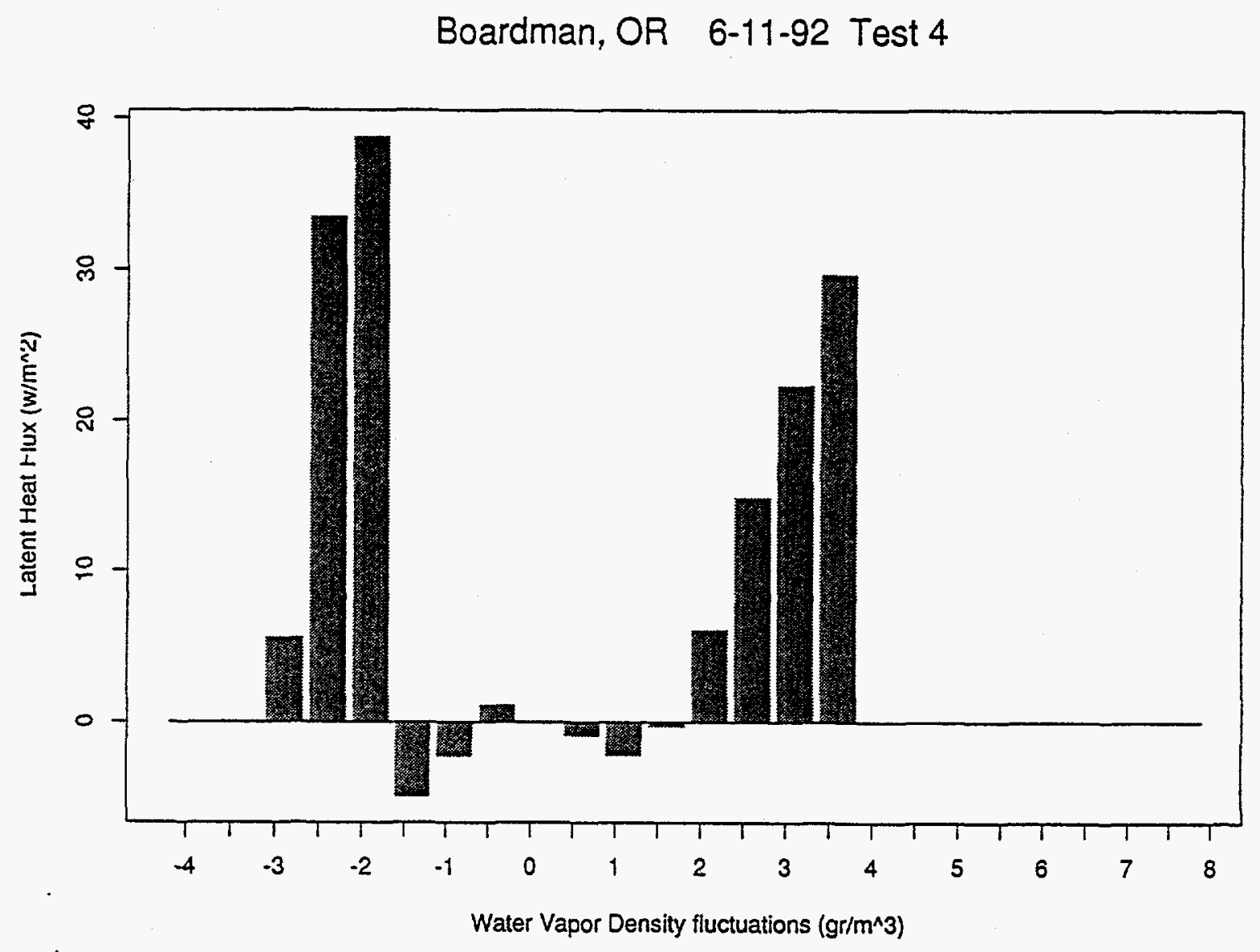

Figure A.4. Contribution to the total latent heat flux categorized by water vapor density fluctuations from the mean, for a 27 -minute period on June 11. 


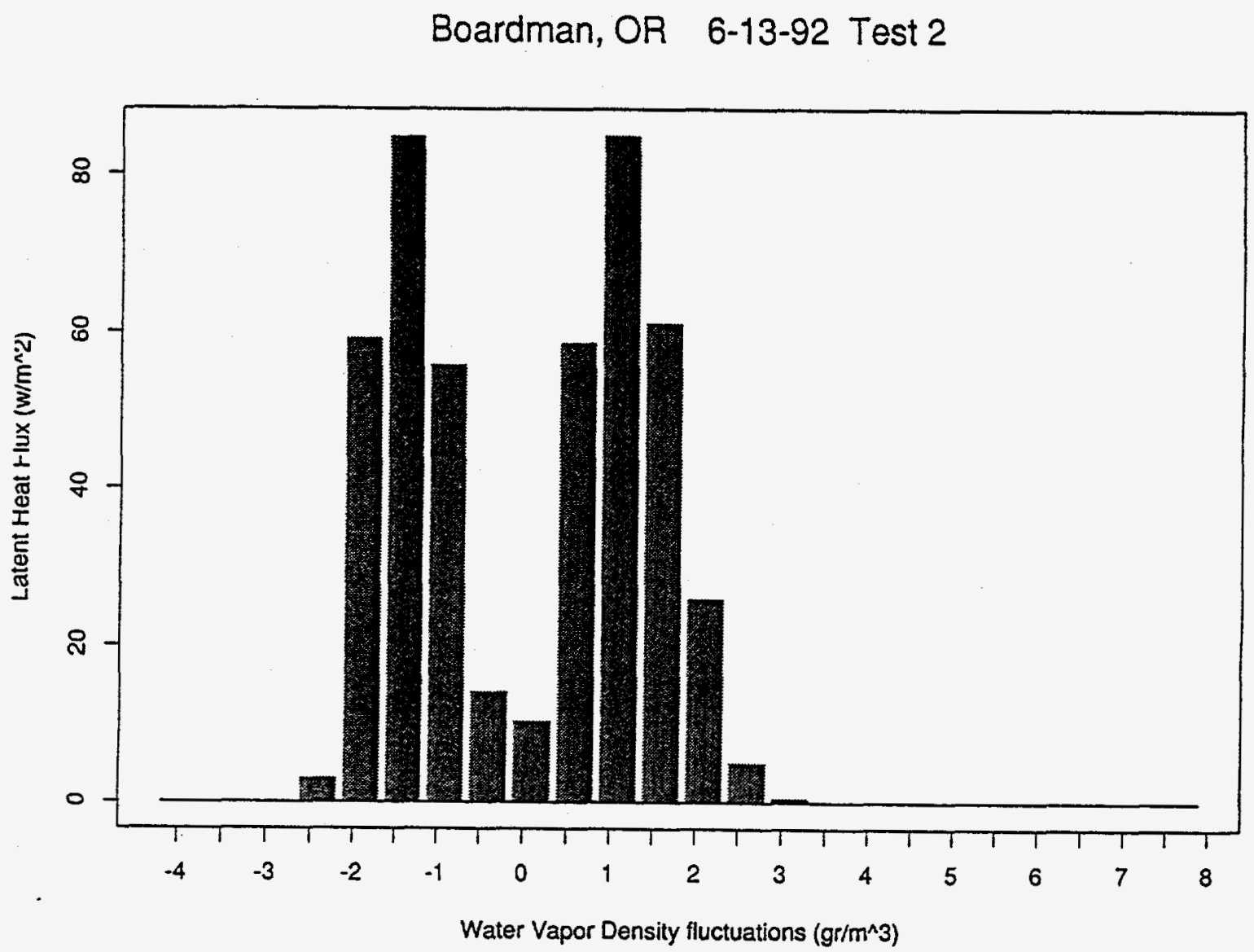

Figure A.5. Contribution to the total latent heat flux categorized by water vapor density fluctuations from the mean, for a 27 -minute period on June 13 . 


\section{Boardman, OR 6-13-92 Test 3}

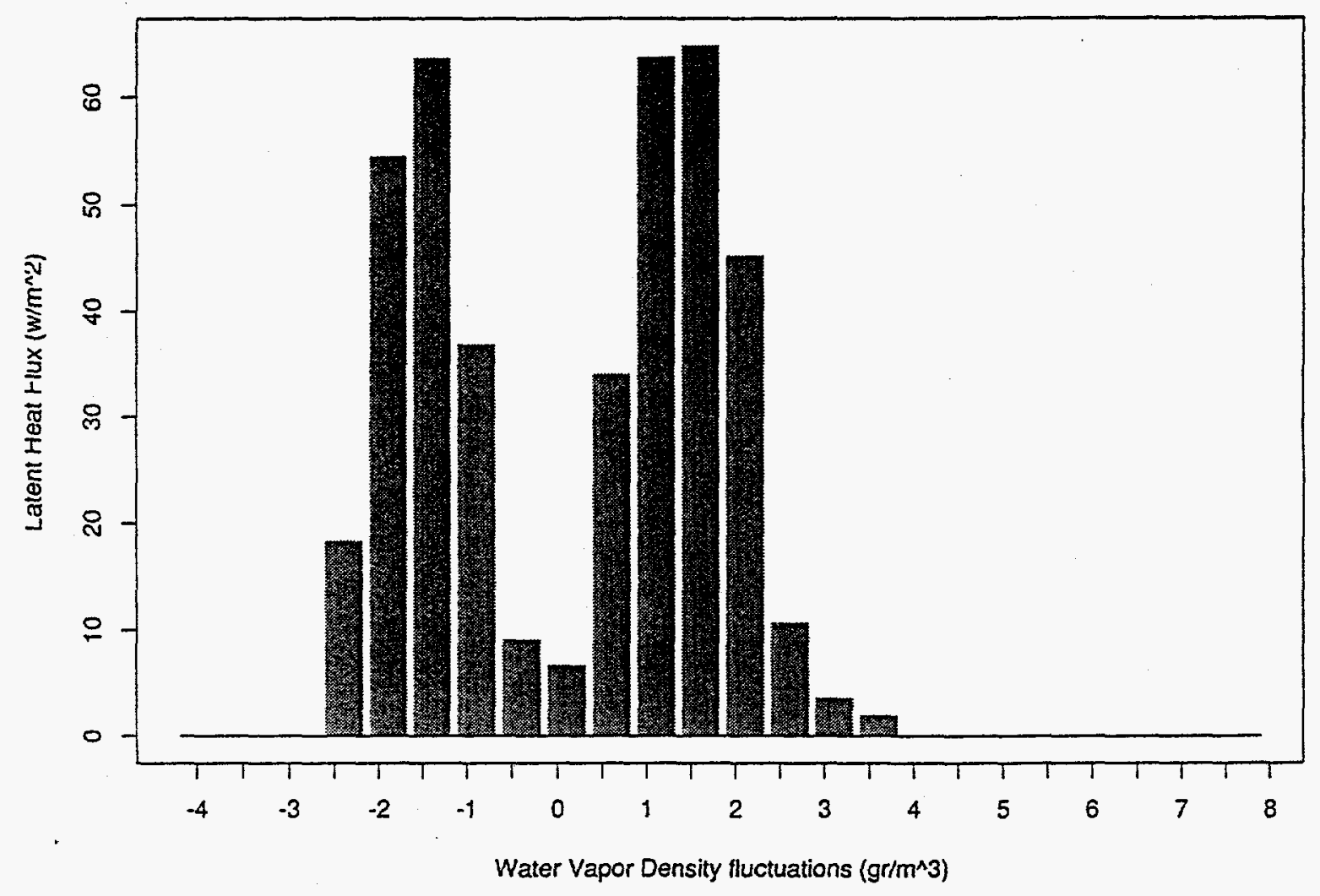

Figure A.6. Contribution to the total latent heat flux categorized by water vapor density fluctuations from the mean, for a 27 -minute period on June 13 . 


\section{Boardman, OR 6-13-92 Test 4}

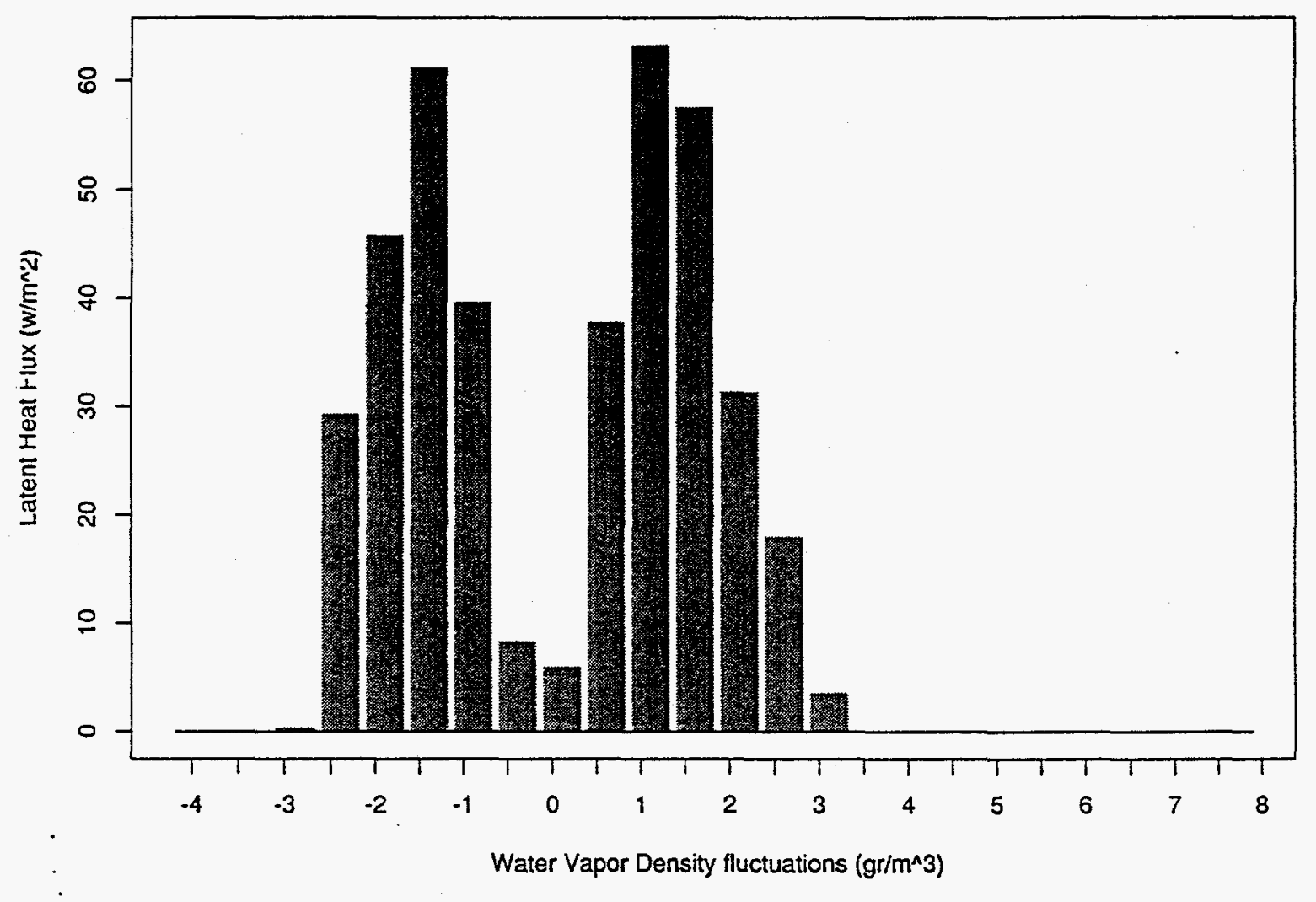

Figure A.7. Contribution to the total latent heat flux categorized by water vapor density fluctuations from the mean, for a 27 -minute period on June 13 . 